Roger D. Traub*, Friederike Moeller, Richard Rosch, Torsten Baldeweg, Miles A. Whittington and Stephen P. Hall

\title{
Seizure initiation in infantile spasms vs. focal seizures: proposed common cellular mechanisms
}

https://doi.org/10.1515/revneuro-2019-0030

Received March 5, 2019; accepted June 1, 2019

\begin{abstract}
Infantile spasms (IS) and seizures with focal onset have different clinical expressions, even when electroencephalography (EEG) associated with IS has some degree of focality. Oddly, identical pathology (with, however, age-dependent expression) can lead to IS in one patient vs. focal seizures in another or even in the same, albeit older, patient. We therefore investigated whether the cellular mechanisms underlying seizure initiation are similar in the two instances: spasms vs. focal. We noted that in-common EEG features can include (i) a background of waves at alpha to delta frequencies; (ii) a period of flattening, lasting about a second or more - the electrodecrement (ED); and (iii) often an interval of very fast oscillations (VFO; $\sim 70 \mathrm{~Hz}$ or faster) preceding, or at the beginning of, the ED. With IS, VFO temporally coincides with the motor spasm. What is different between the two conditions is this: with IS, the ED reverts to recurring slow waves, as occurring before the ED, whereas with focal seizures the ED instead evolves into an electrographic seizure, containing high-amplitude synchronized bursts, having superimposed VFO. We used in vitro data to help understand these patterns, as such data suggest cellular mechanisms for delta waves, for VFO, for seizure-related burst complexes containing VFO, and, more recently, for the ED. We propose a unifying mechanistic hypothesis emphasizing the importance of brain $\mathrm{pH}$ - to explain the commonalities and differences of EEG signals in IS versus focal seizures.
\end{abstract}

\footnotetext{
*Corresponding author: Roger D. Traub, IBM Thomas J. Watson Research Center, Yorktown Heights, NY 10598, USA; and Department of Neurology, Columbia University, New York, NY 10032, USA, e-mail: rtraub@us.ibm.com

Friederike Moeller: Department of Clinical Neurophysiology, Great Ormond Street Hospital, London WC1N 3JH, UK

Richard Rosch: MRC Centre for Neurodevelopmental Disorders, King's College London, New Hunt's House, London SE1 1UL, UK Torsten Baldeweg: Institute of Child Health, University College London, 30 Guildford Street, London WC1N 1EH, UK

Miles A. Whittington and Stephen P. Hall: Hull York Medical School, University of York, Heslington Y010 5DD, UK
}

Keywords: electrodecremental response; fast oscillations; intracranial EEG.

\section{Introduction}

Infantile spasms (IS) can occur idiopathically or in association with defined pathologies such as tuberous sclerosis (TS) or focal cortical dysplasias (FCD). [Both of these latter conditions can occur as so-called 'mTORopathies' (Crino, 2015); mTOR is 'mammalian (or mechanistic) target of rapamycin'.] TS and FCD will be considered in this review. The incidence of IS has been estimated as about 0.31 per 1000 live births, with average age of onset of 6 months (Hrachovy and Frost, 2013), and the condition affects about 1 in 2000 infants (Kossoff, 2010). Spasms can also be seen beyond the first year of life and epileptic spasms can persist into childhood (Sotero de Menezes and Rho, 2002; Ramachandrannair et al., 2008). About $30 \%$ of TS patients present with IS (Saxena and Sampson, 2015). Of course, IS can occur in association with many disease states besides TS and FCD, including, but not limited to, lissencephaly (Herbst et al., 2016), Down syndrome (Daniels et al., 2019), mutations in the CDKL5 gene (Jdila et al., 2017), mutations of the STXBP1 gene (Li et al., 2018), and hypoxic-ischemic encephalopathy (Inoue et al., 2014). In this review, we attempt to illuminate the possible physiological mechanisms of epileptic spasms in general - mechanisms that may occur as a convergent pathology secondary to a range of primary identified pathologies.

The typical (but not universal) electroencephalography (EEG) pattern of IS (Hrachovy and Frost, 2003) consists of a 'hypsarrhythmia' background of large slow waves, variable in amplitude and frequency, and often containing multifocal EEG spikes (Oka et al., 2004). Interspersed are relatively flat periods, lasting about one or a few seconds, called electrodecrements (EDs; Figure 1). Just before, and extending into the ED, can occur a run of oscillations of lower amplitude and often in the very fast oscillation (VFO) range of more than $70 \mathrm{~Hz}$ (Akiyama et al., 2005; Figure 1). Such oscillations, when they occur, may 


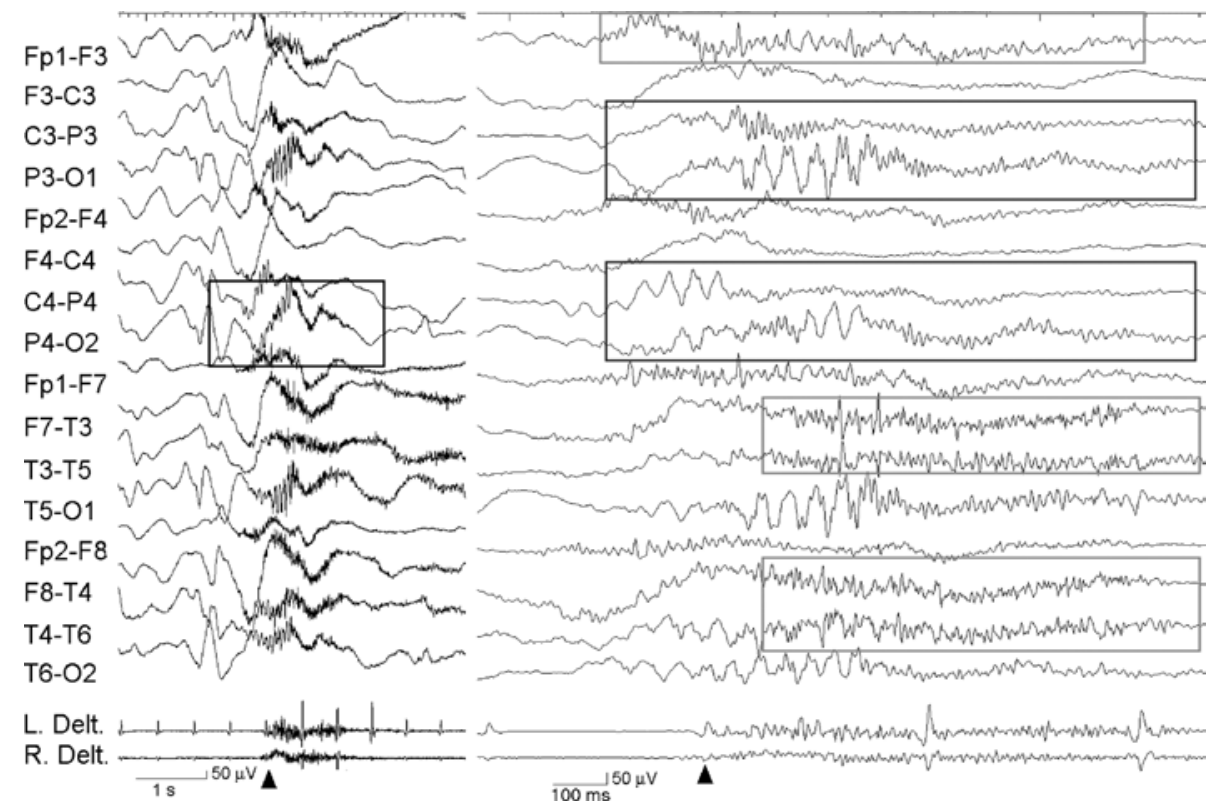

Figure 1: EEG from a child with IS, showing hypsarrhythmia along with VFO associated with ED. Such EDs were followed by a return to hypsarrhythmia. See Figure 4 in Kobayashi et al. (2015).

be temporally correlated with motor spasm (Kobayashi et al., 2015; Figure 1). The frequencies of the oscillations have been reported: peaking at about $70 \mathrm{~Hz}$ (Inoue et al., 2008), 40-150 Hz (Kobayashi et al., 2015), 51-98 Hz and lasting $500 \mathrm{~ms}$ (Kobayashi et al., 2004), and 15-250 Hz (Ramachandrannair et al., 2008). In one study, oscillations at $20-100 \mathrm{~Hz}$ tended to be colocalized with magnetic resonance imaging (MRI) abnormalities (Kim et al., 2018). Some degree of focality for the fast oscillations can be present (Arroyo et al., 1994). IS associated with TS have been proposed to arise from secondary generalization (Curatolo et al., 2001); this may likewise be the case in FCD (Caraballo et al., 2016). In FCD, the presence of hypertrophic neurons in layer 1 has been associated with IS.

\section{EEG phenomenology for IS: irregular delta $\rightarrow$ ED with VFO $\rightarrow$ back to irregular delta}

Figure 1 provides an example (from an IS patient) of the transition from irregular delta to ED with VFO. There is an associated clinical spasm, as evident in the left and right deltoid muscle electromyograms at the bottom of the figure. The full sequence, including reversion to irregular delta, can be seen, for example, in Figure 3 in Kobayashi et al. (2015).

\section{Stereo-EEG (SEEG) phenomenology for focal seizures associated with FCD and TS: background activity $\rightarrow$ ED with VFO $\rightarrow$ electrographic seizure (Mohamed et al., 2012)}

Children with FCD or TS may have rather different EEG (or SEEG) patterns (see Figure 2 and example in Traub et al., 2001), and they may have different associated seizure phenomenologies compared to IS, for example, they may have focal motor or focal seizures with impaired awareness. This is particularly likely to be the case in somewhat older children. Here, the background is not hypsarrhythmia that persists for long intervals. Figure 2 shows an SEEG recording in a patient with an FCD in the left posterior insula. Preictal discharges are seen with electrographic seizure onset (indicated by an arrow) and superimposed fast activity $(80 \mathrm{~Hz})$ is seen over the posterior insula, evolving into rhythmic discharges. Burst complexes during such a seizure themselves exhibit superimposed VFO (Traub et al., 2001). Interestingly, burst suppression has also been reported to occur at seizure onset in a TS patient (Perucca et al., 2014).

VFO in TS is likely to signal pathogenicity of the initiating area (Fujiwara et al., 2016), as is the case for FCD (Traub et al., 2001). In TS, cortical and subcortical pathology includes both the tubers themselves and also more widespread altered cortical cytoarchitecture (Marcotte et al., 2012). There exist conflicting data on whether the 

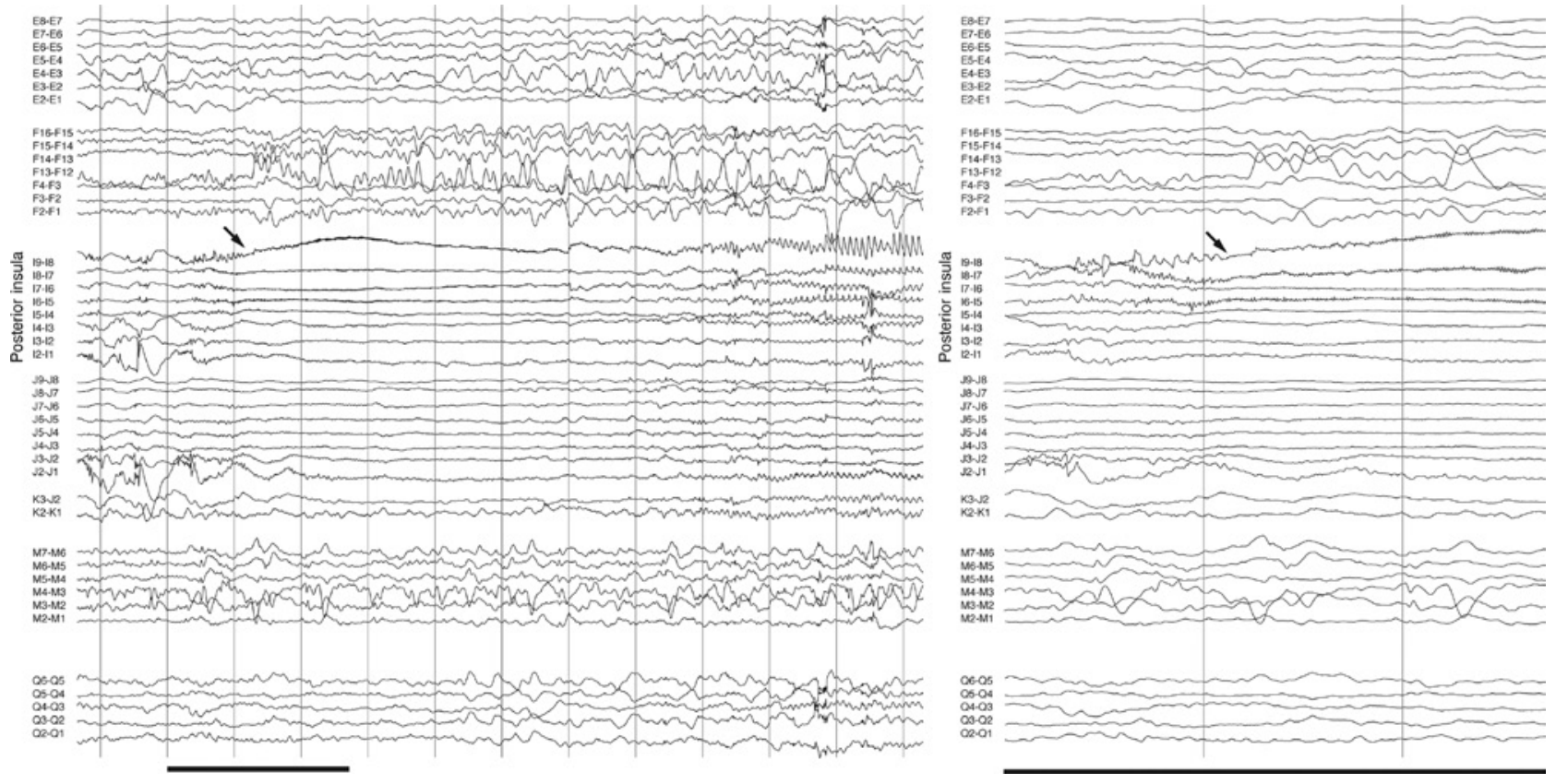

Figure 2: SEEG recording in a patient with an FCD in the left posterior insula.

Preictal discharges are seen with electrographic seizure onset (arrow); ED and superimposed fast activity ( $80 \mathrm{~Hz}$ ) are seen over the posterior insula, evolving into rhythmic discharges. The patient became seizure free after resection of the posterior insula.

tubers themselves are epileptogenic (Major et al., 2009; Mohamed et al., 2012; Kannan et al., 2016).

Summarizing this section, the EEG patterns of IS and focal seizure onset (at least with TS and FCD) share 'highamplitude slow waves' (persistent in IS, background activity for the focal case), 'flattening or ED responses', and 'fast oscillations'. The hypsarrhythmic EEG pattern additionally contains EEG spikes and, at least in some children, evolves with the maturation out of a burst suppression pattern (Yamatogi and Ohtahara, 1981; Ohtahara and Yamatogi, 2003). In this paper, we shall regard hypsarrhythmia and burst suppression as forming part of a spectrum, as both contain large slow waves with intervals of EEG flattening - such intervals occurring irregularly in hypsarrhythmia and more periodically (and perhaps lasting longer) in burst suppression.

\section{Three hypotheses}

In this review, we consider three interrelated hypotheses that, taken together, could account for the above clinical observations. The hypotheses derive from in vitro experimental data on delta waves, VFO, pyramidal cell depolarizing plateaus, and epileptiform bursts; network modeling has also contributed to our understanding of the experimental data.
Hypothesis 1: Neocortical ED occurs because layer 5 (L5) intrinsic bursting (IB) pyramidal neurons develop sustained depolarizing plateaus, which suppress delta and flatten the EEG. This would stand in contrast to the more conventional hypothesis of EDs resulting from the hyperpolarization of principal neurons.

Hypothesis 2: Tissue conditions (including alkaline $\mathrm{pH}$ and glutamate release), which favor the ED, also favor VFO generated by superficial pyramidal neurons.

Hypothesis 3: If, during the ED, VFO persists and sufficient superficial disinhibition develops (Hall et al., 2015), an electrographic seizure will occur.

We shall now review in vitro data that support the three hypotheses: data on delta rhythms, plateaus, VFO, and seizure-like phenomena.

\section{Cellular mechanisms of delta rhythm (in vitro): rhythmic population bursts in L5 IB pyramidal neurons; behavior of layer $2 / 3$ (L2/3) pyramidal neurons during 'normal' delta and after disinhibition of superficial cortical layers: the emergence of EEG spikes}

We have developed an in vitro model of neocortical delta rhythms using rat cortical slices bathed in a low concentration of carbachol ( $2 \mu \mathrm{M}$; a cholinergic agonist) and 
A

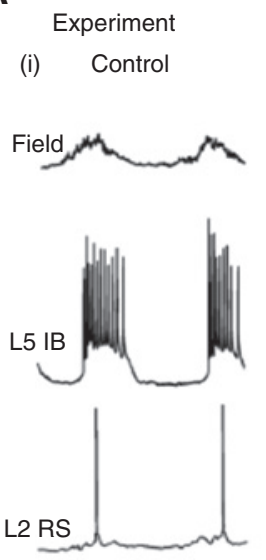

(ii)

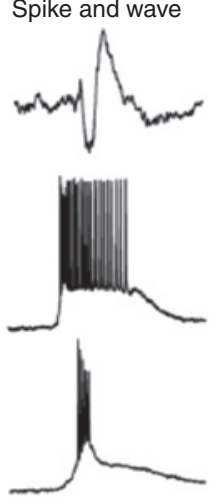

B

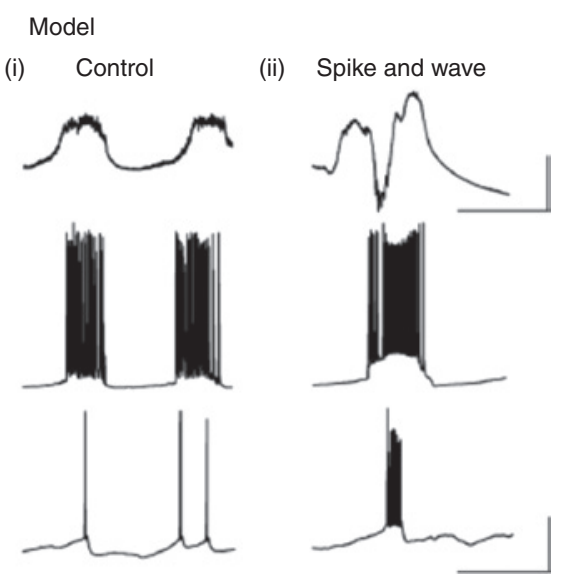

Figure 3: Experimental (A) in vitro and network-simulated (B) deep cortical delta rhythm and its conversion to spike-wave.

'Control': in vitro delta produced by L5 IB pyramidal neurons. Superficial pyramidal cells follow with EPSPs or single spikes. The neocortical slice was bathed in a low concentration of carbachol $(2 \mu \mathrm{M})$ and a dopamine D1 receptor antagonist (SCH23390; $10 \mu \mathrm{M})$. Delta is expressed by intense bursts in L5 IB pyramidal cells but with single spikes or synaptic potentials in superficial pyramidal cells. 'Spike and wave': in the experiment, dTC $(10 \mu \mathrm{M})$ was applied to block nicotinic acetylcholine and $5-\mathrm{HT}_{3}$ receptors, reducing superficial NPY actions among other things. In the model, superficial synaptic inhibition was reduced, whereas superficial recurrent excitation enhanced. These treatments convert delta to spike-wave, during which the deep delta continues relatively unaltered. Scale bar, $0.3 \mathrm{mV}$ (experimental field), $20 \mathrm{mV}$ intracellular, 0.3 s. From Figure 2 in Hall et al. (2015).

a dopamine D1 receptor antagonist (SCH23390; $10 \mu \mathrm{M}$; Carracedo et al., 2013; Hall et al., 2015; Figure 3). This experimental delta rhythm is generated by L5 IB pyramidal neurons, which each generate a burst of action potentials during every delta wave. The experimental delta rhythm requires both $N$-methyl-D-aspartate (NMDA) and $\mathrm{GABA}_{\mathrm{B}}$ receptors. Regular spiking (RS) pyramidal cells, both deep and superficial, do not burst during the delta rhythm, instead producing synaptic potentials or one (sometimes two) action potentials per wave. Interestingly, in vitro delta can transform into spike-wave, as happens in children with absence seizures and in rats injected with D-tubocurarine (dTC; a nicotinic receptor antagonist) into the cortex. This latter injection (and also $10 \mu \mathrm{M} \mathrm{dTC}$ in the in vitro bath) suppresses the activity of superficial neuropeptide Y (NPY) interneurons and enhances the activity of vasoactive intestinal peptide (VIP) interneurons; these effects will produce a relative disinhibition in the superficial cortex as well as enhance glutamate release in superficial layers (Wang, 2005; Hall et al., 2015). Figure 3 shows that in vitro spikewave is correlated with bursts in superficial pyramidal cells, while the underlying deep delta rhythm continues. Interestingly, TS has been associated with a reduction in NPY interneurons (Fu et al., 2012), so that it is possible that chronic superficial cortical disinhibition exists in TS.

It is difficult to prove that the cellular mechanisms of delta waves, as occur during hypsarrhythmia, are identical to those elucidated in vitro; certainly, in vitro delta is qualitatively more regular in amplitude and frequency than the patient EEG rhythm. Perhaps in vitro experiments on human TS tissue removed at surgery could provide supporting evidence. Additionally, magnetoencephalography (MEG) technology is advancing rapidly [for example, with wearable sensors (Boto et al., 2018)], and recently developed mathematical methods allow one to determine the laminar origins of certain MEG signals (Bonaiuto et al., 2018); finding maximum power of hypsarrhythmic delta in L5 would be supportive of a relationship between in vitro and in vivo rhythms (see Figure 1 in Carracedo et al., 2013). In the meantime, we argue that in vitro delta [and spike-wave (Hall et al., 2015)] is the most suitable experimental model for now until contravening data appear.

Given the age-dependent expression of IS and the NMDA receptor dependence of in vitro delta (Carracedo et al., 2013), it is interesting that EEG delta is more prominent in infants than in older children and adults (Ogawa et al., 1984; Olbrich et al., 2017) likely due to developmental differences in the expression of NMDA receptor subunits (Yashiro and Philpot, 2008). Likewise of interest, given that FCD can be associated with IS, is the altered NMDA receptor subunit composition in cortical dysplasia tissue (André et al., 2004) as well as the reduced $\mathrm{Mg}^{2+}$ sensitivity of NMDA receptors in this tissue (Cepeda et al., 2006, 2007). Gain-of-function mutations in GRIN2B (the gene coding for 'glutamate ionotropic receptor NMDA type subunit 2B') have been linked to IS (Lemke et al., 2014). 


\section{Plateau potentials in L5 IB pyramidal neurons can occur in the presence of trimethylamine (TMA), which alkalinizes tissue and blocks some $\mathrm{K}^{+}$channels}

The compound TMA $\left[\mathrm{N}\left(\mathrm{CH}_{3}\right)_{3} ; \quad \mathrm{pKa}=9.80\right]$ has applications in slice electrophysiology, as it causes alkalinization and blocks some $\mathrm{K}^{+}$channels (French and Shoukimas, 1981; Im and Quandt, 1992). We have shown previously that TMA ( $2 \mathrm{mM})$ perfusing a hippocampal slice would allow a tetanic stimulus to induce first transient gamma oscillations $(\sim 40 \mathrm{~Hz})$, then $\mathrm{VFO}$, and then an electrographic seizure - in a pattern resembling the VFO $\rightarrow$ seizure electrocorticographs (ECoGs) recorded in FCD patients (Traub et al., 2001); without TMA in the bathing medium, the tetanic stimulus would evoke only gamma oscillations but not the VFO or seizure (Whittington et al., 1997). Likewise, if the gap junction blocker carbenoxolone (Davidson et al., 1986) was present, even with TMA in the bathing medium, the same tetanic stimulus would again evoke transient gamma but not the VFO or seizure. We interpreted this experimental observation to mean that TMA was acting, at least in part, by opening gap junctions that were $\mathrm{pH}$ sensitive (see below) and that those particular gap junctions were responsible for the VFO (Draguhn et al., 1998; Traub et al., 1999; Cunningham et al., 2012); however, we did not attempt to explain the electrographic seizure in those experiments.

More recent experiments show that when TMA $(10 \mathrm{~mm})$ is added to a particular bathing medium of a neocortical slice - a medium that induces either delta or spike-wave (see Figure 3) - then a burst suppressionlike field pattern develops, which includes prominent delta as well as VFO during the burst phases; in association with this burst suppression-like pattern, voltage-dependent plateau potentials can develop in L5 IB pyramidal cells (Figures 4 and 5). Because delta in vitro is generated by L5 IB neurons (see Figure 3), it is not surprising that such L5 IB plateaus (Figure 5) abolish the delta, which exists 'in the background' between plateau potentials (Figure 4C). We suggest, therefore, that if the delta of IS patient hypsarrhythmia is similar to in vitro delta, then widespread plateau potentials, in L5 IB neurons, could account for the ED response. Although delta is suppressed during the plateau, VFO can still be recorded in superficial layer field potential recordings (Figure 4). This experimental observation is likely relevant to the VFO that is recorded clinically during an
ED (Figures 1 and 2) and that is temporally correlated with motor spasms.

The notion that EEG flattening (the ED response) is associated with a significant depolarization of selected large pyramidal neurons, rather than hyperpolarization, is - we believe - novel and interesting.

The biophysical mechanisms of the above-illustrated plateaus are not known, but some likely possibilities, as discussed further on, include the enhancement of one or more types of $\mathrm{Ca}^{2+}$ conductance $\left(\mathrm{g}_{\mathrm{Ca}}\right)$, blocking of one or more types of $\mathrm{K}^{+}$conductance $\left(\mathrm{g}_{\mathrm{K}}\right)$, and reduction of $\mathrm{GABA}_{\mathrm{B}}$ receptor signaling.

Given that in vitro cellular plateaus are induced in the presence of TMA, which alkalinizes, it may be relevant that $\mathrm{pH}$ fluctuates in the brain under normal conditions (Magnotta et al., 2012), and this is likely to be especially true in brains with structural and/or functional abnormalities; however, as we argue further on, this issue requires further study.

Plateau potentials in L5 IB neurons might be expected to provide powerful synaptic drive to downstream neurons; however, we must note that the effective axonal output during plateaus is not known. Despite neuronal somata staying in the depolarization block, there is a reason to think that the axons might nevertheless be firing at high frequencies (Williams and Stuart, 1999; Apostolides et al., 2016). In contrast, even if this were to be the case, postsynaptic effects of such high-frequency firing might not be sustained due to glutamate depletion at presynaptic terminals (Staley et al., 1998) or postsynaptic receptor desensitization (Colquhoun et al., 1992).

In the following, we shall be considering a computational model as well as in vitro experimental data. The computational model is based on the extensions of an earlier thalamocortical network model (Traub et al., 2005). Figure 6 shows, for reference, a schematic of the major cell types in the network model, which includes superficial pyramidal cells (g), deep tufted IB and RS pyramidal cells (e), deep nontufted RS cells, and a variety of deep and superficial interneuron types (Carracedo et al., 2013; Hall et al., 2015; see also Traub et al., 2005; Hall et al., 2018). The thalamic component of this model will not be considered here, as we do not have data on thalamic contributions to the phenomena discussed in this paper. Gap junctions occur only between homologous cell types in our model (e.g. L5 IB to L5IB). The synaptic network is too complex to illustrate in a figure, and the reader is referred to the original papers. 
A

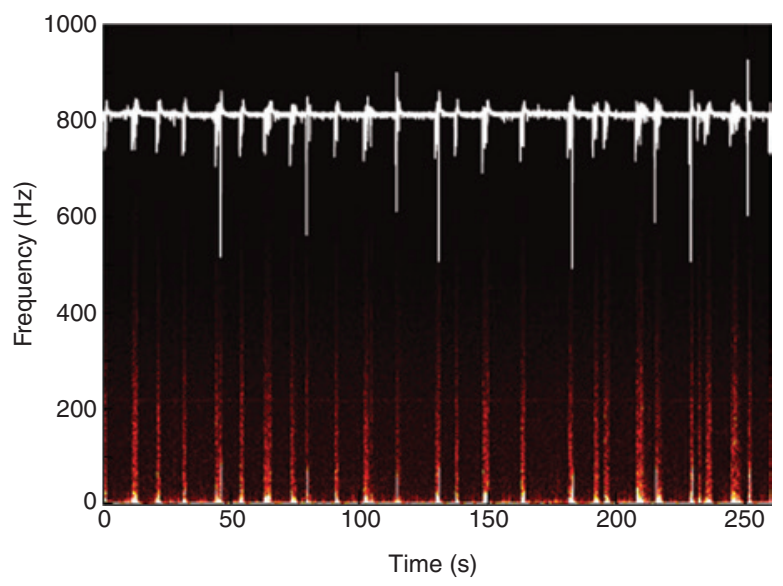

B

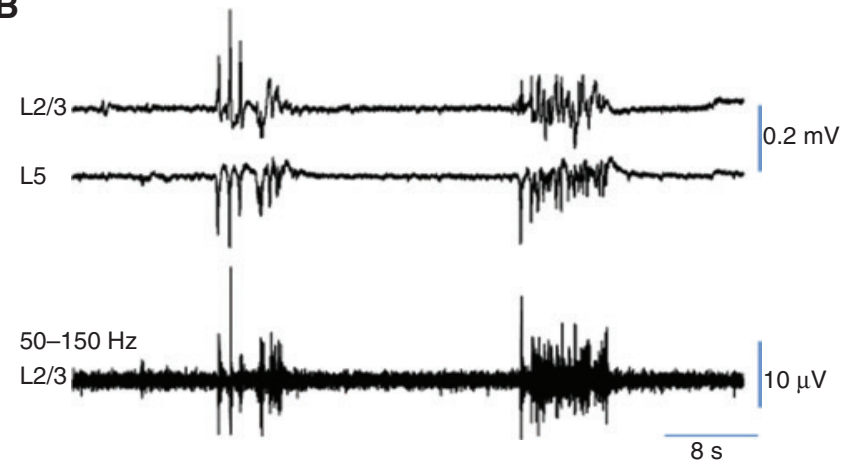

C

(i) MWWWWWMWMWMWN/ $0.2 \mathrm{mv}$

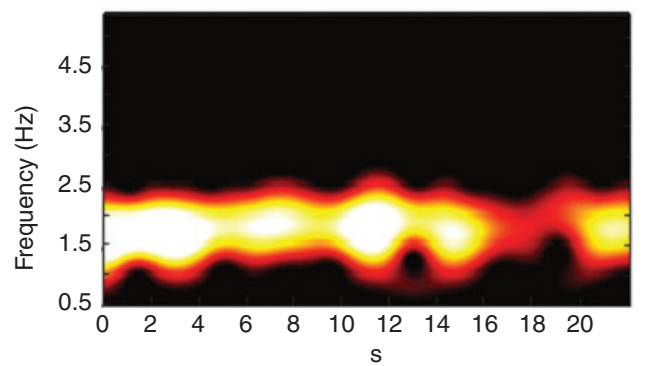

(ii)
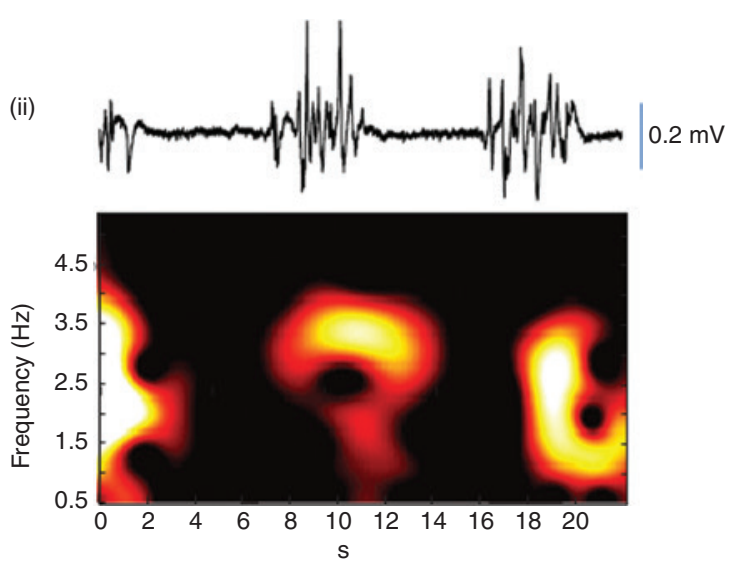

Figure 4: Burst suppression-like discharge pattern in neocortex in vitro associated with superficial VFO and marked reduction in delta activity during the suppression phase.

(For slice conditions, see Methods.) (A) spectrogram of $250 \mathrm{~s}$ of burst suppression transitions, showing epochs of high-frequency activity corresponding to the bursts. Recording used to generate the spectrogram is overlaid in white. (B) Example of two consecutive concurrently recorded burst phases, separated by a suppression phase, in superficial (L2/3) and deep (L5) association neocortex. Bottom trace shows a bandpass-filtered $(50-150 \mathrm{~Hz}$ ) version of the $\mathrm{L} 2 / 3$ field above. (C) Disruption of delta-frequency local field potential activity during bursts of activity and abolition during the ED response. (i) $22 \mathrm{~s}$ trace of control, delta frequency activity recorded from L5, example data shown above the corresponding spectrogram. (ii) $22 \mathrm{~s}$ trace of burst/ED sequences from the same electrode in L5 of the same slice after the application of TMA and dTC. S.P. Hall and M.A. Whittington, unpublished data.

\section{VFO can occur in the neocortex, involving pyramidal neurons, in alkaline conditions without chemical synapses; neocortical VFO is thus plausibly generated by gap junctions between pyramidal neurons}

Clinical EEG recordings, as discussed above, demonstrate that ED responses and VFO can occur simultaneously. If it is true that an ED is caused by the tissue conditions that induce plateaus in vitro, then those same (or similar) conditions might then induce VFO in vitro. We have already mentioned how the alkalinizing compound TMA potentiates VFO in the hippocampal slice after a tetanic stimulus (Traub et al., 2001). In addition, the pressure ejection of an alkaline solution onto L5 of a neocortical slice, during the blockade of chemical synapses, also elicits VFO (Figure 7 in Traub et al., 2010); the intracellular correlate in L5 IB pyramidal cells is a run of action potentials and spikelets (resembling miniature action potentials). Spikelets have been shown, in at least some instances, to originate in axons (Schmitz et al., 2001). A computational network model (see model schematic in Figure 6), using only L5 IB cells (Figure 7, right), produces behavior remarkably similar to the experiment, when simulated IB cells are electrically coupled (with gap junctions) by their axons, and chemical synapses are simultaneously blocked.

Another example of the induction of VFO by the pressure ejection of alkaline solution, with chemical synapses blocked, is shown in Figure 8 (right; from Cunningham et al., 2012); the difference from Figure 7 is that, in Figure 8 , the VFO frequency steadily increases, what we call 'glissando'. Interestingly, when the alkaline pressure ejection 
A
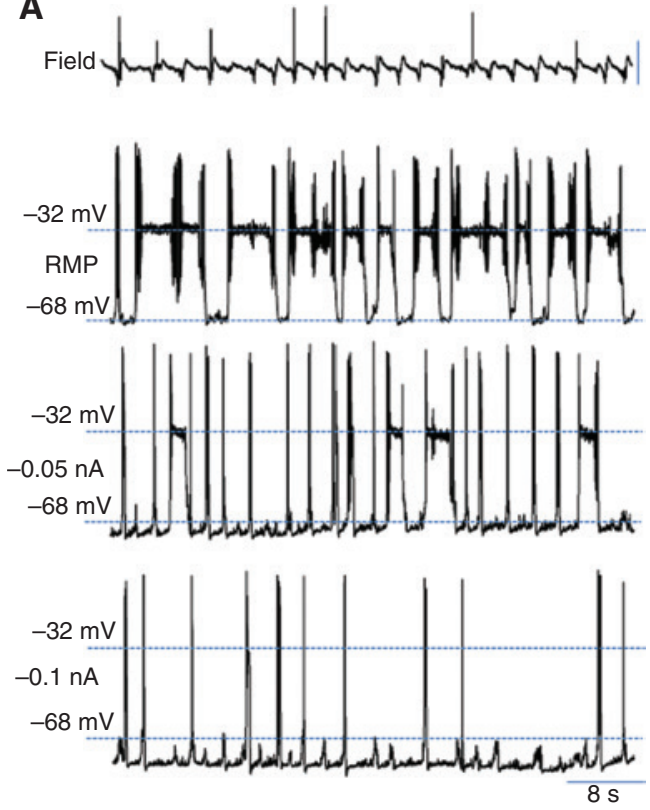

B

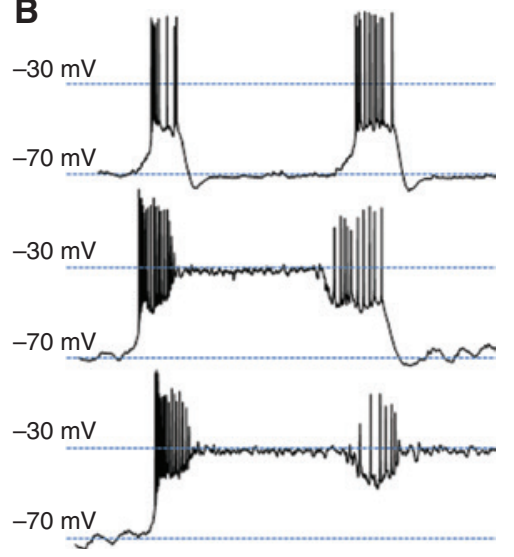

C

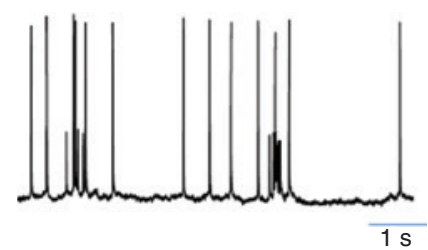

Figure 5: Plateau potentials occur in L5 IB cells when there is a delta oscillation, superficial disinhibition, and tissue is alkaline; the plateau potentials are voltage dependent.

[The bathing medium was as for spike-wave conditions in Figure 3, with the addition also of TMA (10 mM): see Methods.] (A) $60 \mathrm{~s}$ epochs of concurrently recorded L5 field (upper trace) and IB neuron at resting membrane potential (RMP), showing that quiescent (ED) periods of the field potential accompany strongly depolarized plateau potentials. The bottom two example traces show the effect of tonic hyperpolarizing current injection on plateau formation in the same IB neuron, with increasing failure to generate plateaus with increasing hyperpolarization. (B) Examples of plateau behavior between two consecutive burst discharges. Note that the population discharges can fail or can succeed in both generating a plateau and acting as a terminating stimulus: the top example shows a failure of burst discharges to generate a plateau; the middle example shows a successful plateau termination terminated by the next burst; the bottom example also shows a successful plateau generation but with a failure to reset membrane potential on the occurrence of the second burst discharge. (C) Example recording of an L5 RS neuron, revealing intense spikelet discharges; the latter were correlated with bursts in the field (not shown). S.P. Hall and M.A. Whittington, unpublished data.

is applied in the presence of putatively 'normal' synaptic transmission (Figure 8, left), VFO occurs that is 'messier' (in the time-frequency plot); the 'messy' VFO is, however, followed by an electrographic seizure. [A quite similar 'glissando' behavior has been observed in situ in epilepsy patients (cf. Figure 3 in Grinenko et al., 2018).] The entire pattern of Figure $8 \mathrm{~B}$ is also reminiscent of the VFO $\rightarrow$ seizure sequences illustrated for an FCD patient in Traub et al. (2001). These data suggest, then, that the tissue conditions favoring VFO, together with functioning excitatory synapses, would also favor electrographic seizures.

Spontaneous VFO has been reported to occur in the deep neocortex $(0.8 \mathrm{~mm}$ depth) in the cat in vivo just before and during an EEG spike that was the initial part of a spontaneous seizure (Grenier et al., 2003, their Figure 2); the cat was anesthetized with ketamine/xylazine. The brain $\mathrm{pH}$ during this in vivo experiment was not determined. These data do suggest, however, that the VFO $\rightarrow$ seizure sequence may be a general (if not universal) phenomenon.

\section{VFO can occur in the superficial layers of the human neocortex spontaneously, where it is blocked by carbenoxolone (a gap junction blocker)}

It is possible that the VFO observed in clinical contexts, in IS and focal seizure disorders, arises from the superficial layers of the cortex, and not from deep layers, as in the experimental model of Figure 7. Certainly, if VFO occurs simultaneously with plateau potentials in L5 IB neurons, then those latter neurons are unlikely to be the ones generating the VFO; of course, deep RS pyramidal neurons might, in principle, be responsible.

Does superficial VFO ever occur in vitro? The fact that spikelets occur in superficial pyramidal cells (Cunningham et al., 2004; Roopun et al., 2010) suggests that VFO might occur there as well. The superficial VFO in vitro after an EEG spike in media including TMA (Figure 4B above) also implies that VFO can be generated in 


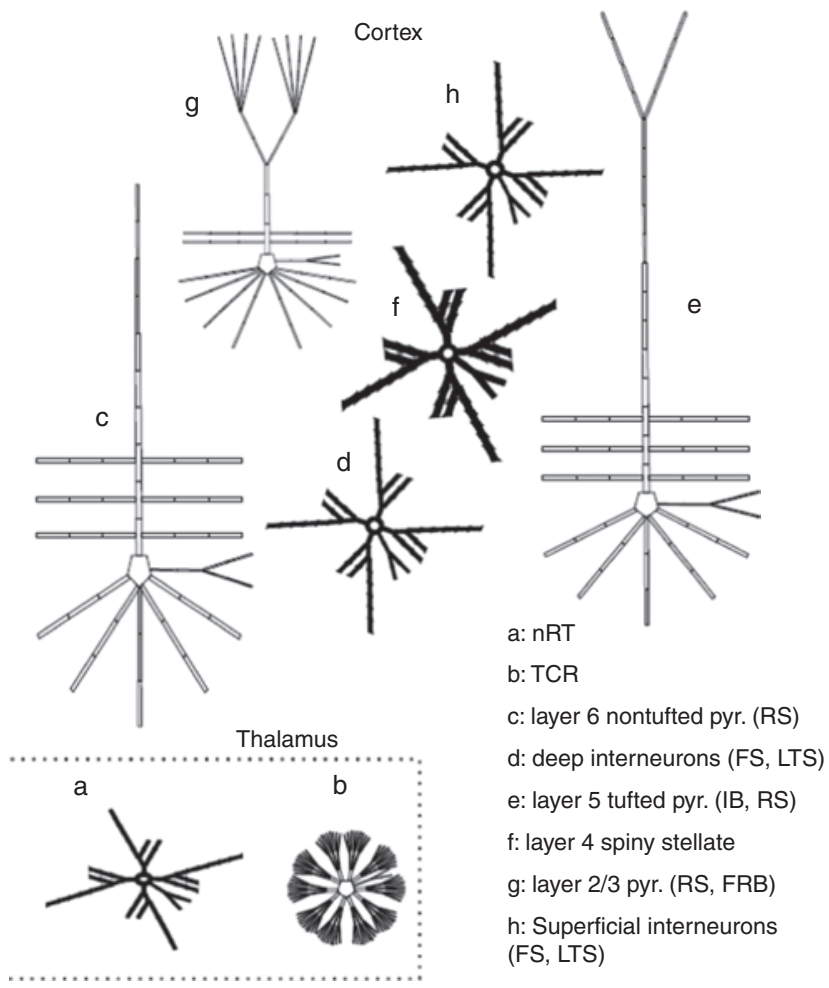

Figure 6: Schematic of cell types included in the computational network model of neocortical column (the thalamic portion of the model was not used for this paper).

From Traub et al. (2005).

superficial cortical layers. Furthermore, as Figure 9 shows (from Figure 4 in Simon et al., 2014; scale bar, 1 mm), VFO can occur spontaneously in the superficial layers of the human neocortex, removed surgically from an epilepsy patient - this without specific manipulation of the $\mathrm{pH}$. The VFO, in this case, was suppressed by the gap junction blocker carbenoxolone, a drug that - like all gap junction blockers - has some nonspecific side effects (Tovar et al., 2009). In the experiments of Simon et al. (2014) on human tissue, VFO was also observed in deep layers but not as often as in superficial layers. Overall, the in vitro data of Figure 9 can be seen as an 'existence proof' that VFO can occur in superficial neocortical layers at least in certain conditions.

\section{What are the cellular mechanisms of seizure-related VFO?}

If altered brain $\mathrm{pH}$ is critical for the initiation of seizures, that would be important in itself. The detailed cellular mechanisms would still matter, however, as such details might provide specific clues for treatment or prevention. As we have argued previously (Traub et al., 2001; Traub and Whittington, 2010), considerable experimental data on VFO do suggest one particular cellular mechanism: electrical coupling via gap junctions between the axons of pyramidal neurons. As additional experimental data on this subject have accrued since earlier reviews (Traub et al., 2001, 2002), we here briefly summarize the arguments for the gap junction mechanism, referring also the reader to other more extensive accounts (Traub and Whittington, 2010; Traub et al., 2018). The four main

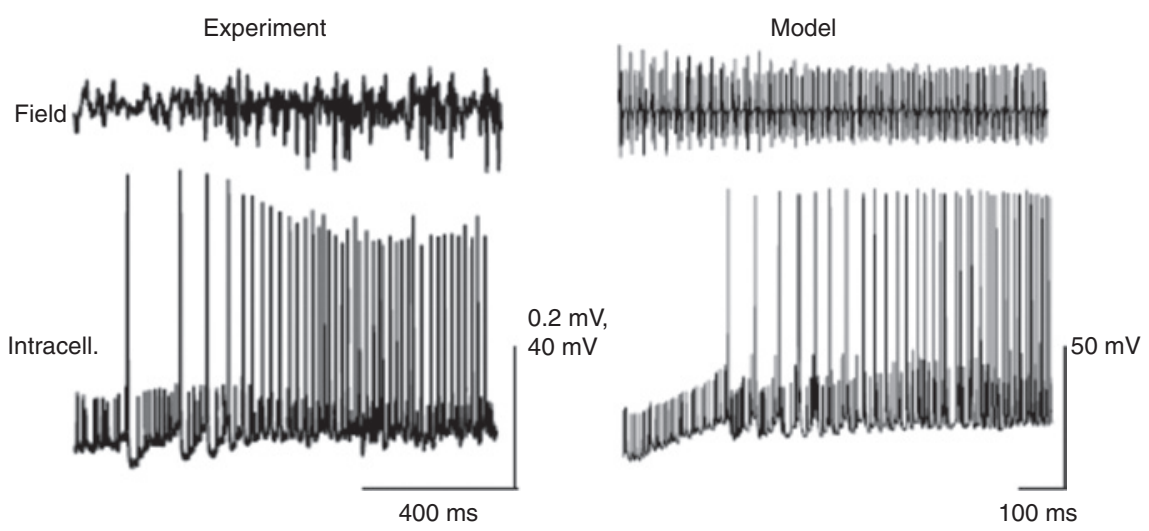

Figure 7: VFO occurs in ensembles of L5 IB cells in alkaline conditions when chemical synapses are blocked. Upper traces are field and intracellular recordings (L5IB). Here, VFO occurs in L5 of rat temporal neocortex with fast chemical synapses blocked: AMPA, NMDA, and GABA ${ }_{A}$ receptors were blocked with SYM2206, AP5, and gabazine, respectively. The bath contained kainate and alkaline ACSF was pressure ejected onto the slice just before the trace begins. Scale bar, $0.2 \mathrm{mV}$ (field), $40 \mathrm{mV}$, and $400 \mathrm{~ms}$. Simulation data are shown on the right: field potential of very fast network oscillation (top; spectral peak at $112 \mathrm{~Hz}$ ) and simultaneous 'intracellular recording' (bottom). Scale bar, $50 \mathrm{mV}$ (cell), $100 \mathrm{~ms}$. A mixture of full action potentials and spikelets occurs, as in the experiment. The model consisted of 15000 multicompartment IB pyramidal cells, with gap junctions between axons. A ramping bias current ( -0.5 to $0.5 \mathrm{nA})$ was applied to the illustrated cell to show that spikelets are more common at hyperpolarized somatic membrane potentials and full spikes at depolarized membrane potentials. From Figure 1 in Traub et al. (2010). 


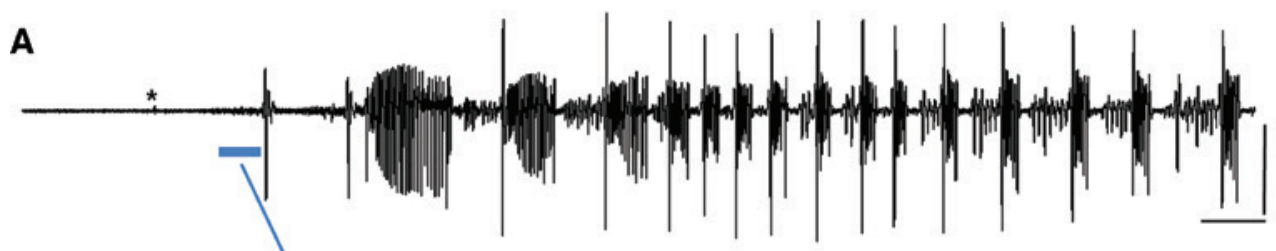

B

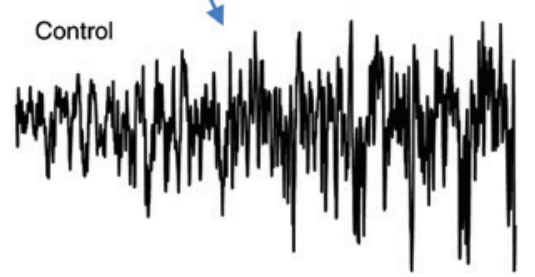

Chemical transmission blocked
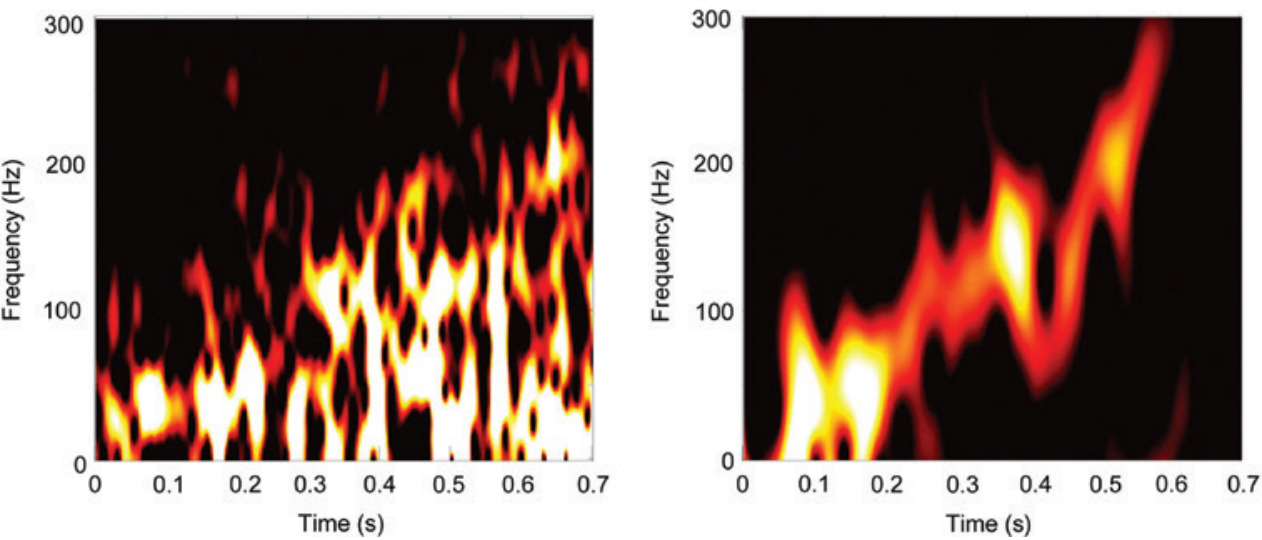

Figure 8: Transient alkalinization in neocortex in vitro can evoke VFO followed by an electrographic seizure, with functioning chemical synapses; with phasic chemical transmission blocked, only the VFO occurs (in this case, with steadily increasing frequency, a 'glissando'). (A) Rat frontal cortex maintained in normal ACSF. Transient alkalinization was induced by pressure ejection of 30-70 nl ACSF containing $200 \mathrm{~mm} \mathrm{NaOH}$ (asterisk). This induced a gradual increase of fast spontaneous activity with an increasing peak frequency until the onset of ictal event lasting $>60 \mathrm{~s}$. Scale bar, $1 \mathrm{~s}, 2 \mathrm{mV}$. (B) Comparison of 'glissando' discharges evoked in normal conditions and conditions with the main chemical synaptic components blocked (gabazine for $\mathrm{GABA}_{A}$ receptors, CGP35348 for $\mathrm{GABA}_{B}$ receptors, NBQX for AMPA receptors, and R-CPP for NMDA receptors). The left trace is expanded from ' $A$ ' and the corresponding spectrogram shown below. The right trace shows the response to the same alkalinizing ACSF pulse with the synaptic blockers as above. Scale bar, $0.1 \mathrm{~V}, 100 \mathrm{~ms}$. Note the absence of slower frequencies as the glissando progresses during the blockade of chemical synapses and the failure to progress to full electrographic seizure. From Figure 3 in Cunningham et al. (2012).

observations supporting the role of pyramidal cell gap junctions in VFO are as follows:

1. VFO occurs in vitro with chemical synapses blocked with the suppression of the VFO by gap junction blockers (Draguhn et al., 1998; see also examples above). With chemical synapses blocked, interneurons did not participate in VFO (Draguhn et al., 1998).

2. Pair recordings between pyramidal neurons, in the hippocampus and neocortex, demonstrate powerful electrical coupling, with spikes in one cell evoking spikes in the other (Mercer et al., 2006; Wang et al., 2010).

3. Stimulation in the stratum oriens of the hippocampus in vitro evokes spikelets in pyramidal cells under the conditions of chemical synaptic blockade; the spikelets are blocked by carbenoxolone or intracellular acidification; the spikelets result from partially blocked antidromic action potentials (Schmitz et al., 2001). These observations can be explained if gap junctions occur on axons.

4. Dye coupling has been demonstrated between the axons of CA1 pyramidal neurons (Schmitz et al., 2001).

What might the constitutive gap junction protein be? It is probably not connexin36 (Cx36), the most common neuronal gap junction protein. There are several reasons to consider. First, there is extremely low mRNA expression for Cx36 in CA1 pyramidal neurons (Cembrowski et al., 2016). Second, Cx36 gap junction channels close at alkaline $\mathrm{pH}$ (González-Nieto et al., 2008), whereas VFO is potentiated by alkaline $\mathrm{pH}$ (as discussed above). Third, spontaneous 
A
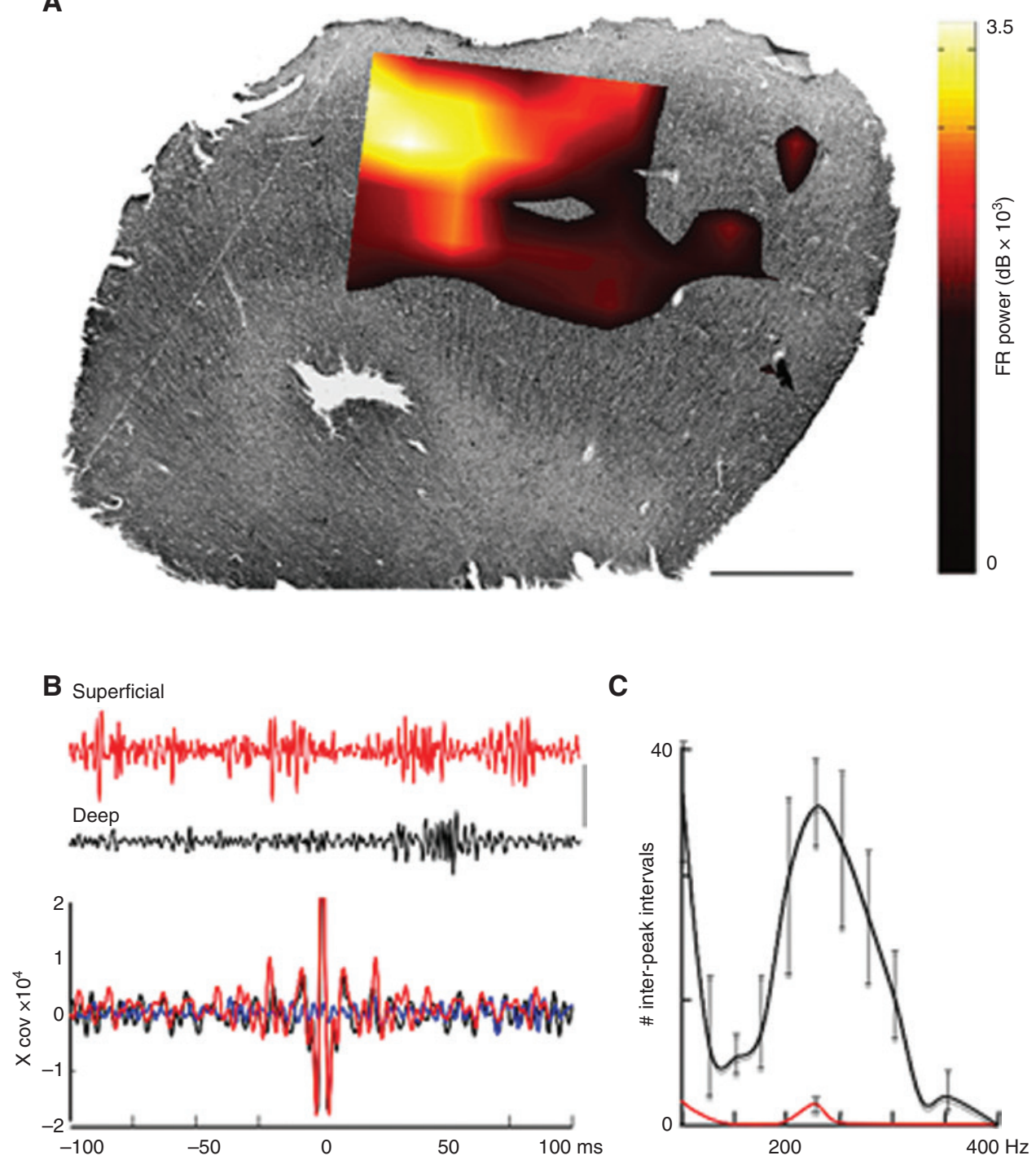

Figure 9: VFO occurs spontaneously in the superficial layers of a human neocortical slice.

(A) Example of the spatial distribution of $>200 \mathrm{~Hz}$ activity in a slice from the human neocortex stained for nonphosphorylated neurofilament. Power at $>200 \mathrm{~Hz}$ is represented as a colormap hard thresholded at $6 \times 10^{3} \mathrm{~dB}$. Scale bar, $1 \mathrm{~mm}$. (B) Concurrently recorded local field potentials (100-400 Hz, $0.5 \mathrm{~s}$ epochs) from superficial (red) and deep (black) electrodes showing a greater incidence of very fast activity in superficial layers. Mean autocorrelations of activity in the superficial and deep layers ( $n=10,0.5$ s epochs each from $n=3$ slices) showing greater incidence of fast ripple activity in superficial layers. Cross-correlations between superficial and deep layers (blue) revealed little temporal interaction between the layers. Scale bar, $50 \mu \mathrm{V}$. (C) The graph shows data from $\mathrm{n}=3$ slices from three patients, demonstrating $>200 \mathrm{~Hz}$ in control conditions (black line) and in the presence of the gap junction blocker carbenoxolone $(0.2 \mathrm{~mm})$. Then, $>200 \mathrm{~Hz}$ frequency events were almost completely abolished by the gap junction blocker carbenoxolone. From Figure 4 in Simon et al. (2014).

VFO ('ripples') appear normal in a Cx36 knockout mouse in vivo (Buhl et al., 2003).

In contrast, a more likely candidate for the requisite gap junction protein is connexin 45 (Cx45). The associated mRNA is found at high levels in CA1 pyramidal neurons (Cembrowski et al., 2016), Cx45 gap junction channels open in alkaline solutions (Palacios-Prado et al., 2010), and alkaline solutions enhance dye coupling between hippocampal pyramidal neurons (Church and Baimbridge, 1991; Perez-Velazquez et al., 1994). Such pH dependence of the $\mathrm{Cx} 45$ gap junction conductance is in accord with the facilitation of VFO by alkaline tissue conditions.

The mechanisms by which electrical coupling can actually produce VFO have been considered previously (Traub et al., 1999; Simon et al., 2014). One such mechanism is called 'percolation' in the field of statistical 
physics. Gap junctional coupling can lead to VFO, at least in principle, when three conditions are satisfied. First, each axon (on average) couples to more than one other axon but not to too many axons; coupling to only two other axons is sufficient. Second, the coupling is strong enough that action potentials in one axon can induce action potentials in coupled axons. Third, there is a background of spontaneously occurring action potentials (so-called 'ectopic spikes'). A key concept is that coupling can be extremely sparse (hence difficult to find in paired intracellular recordings) yet still be able to induce important physiological effects, provided that the coupling is strong enough (Traub et al., 1999; Traub and Whittington, 2010).

\section{Synthesis I: IS case: Network simulation shows how plateau potentials block delta, producing an ED; VFO also occurs simultaneously if gap junctions in superficial neocortical layers are opened (e.g. by alkaline conditions)}

Network simulations have proven useful in helping to understand activities involving multiple neurons, especially when different neuronal types participate, with many sorts of chemical synaptic and electrical interactions (Traub et al., 2005). Models of this sort can make specific predictions that motivate experiments. Extending the recent modeling concerned with in vitro delta rhythms, spike-wave, and polyspikes (Carracedo et al., 2013; Hall et al., 2015, 2018), we performed simulations to examine the interlaminar network effects of plateaus induced in model L5 IB pyramidal neurons. (The details are in the cited papers and in Methods.) Examples of two such simulations are shown in Figures 10 and 11.

In Figure 10, parameters are first set so as to generate delta waves, in a manner similar to that by Carracedo et al. (2013), with L5 IB cells generating bursts of action potentials on each delta wave, whereas superficial (L2/3) RS cells produce synaptic potentials. Following this, transient plateaus are induced in L5 IB cells by manipulating $\mathrm{GABA}_{\mathrm{B}}, \mathrm{K}^{+}$, and L-type $\mathrm{Ca}^{2+}$ conductances (see Methods). These manipulations suppressed delta as expected (see also Figure 4). At the same time as plateaus were induced, the computer program increased gap junction conductances between superficial pyramidal neurons. This manipulation induced superficial VFO $(\sim 230 \mathrm{~Hz}$; see inset), which manifested itself at the cellular level as intense action potential and spikelet generation. Because, in this case, the plateau generation and gap junction changes were 'transient', the system

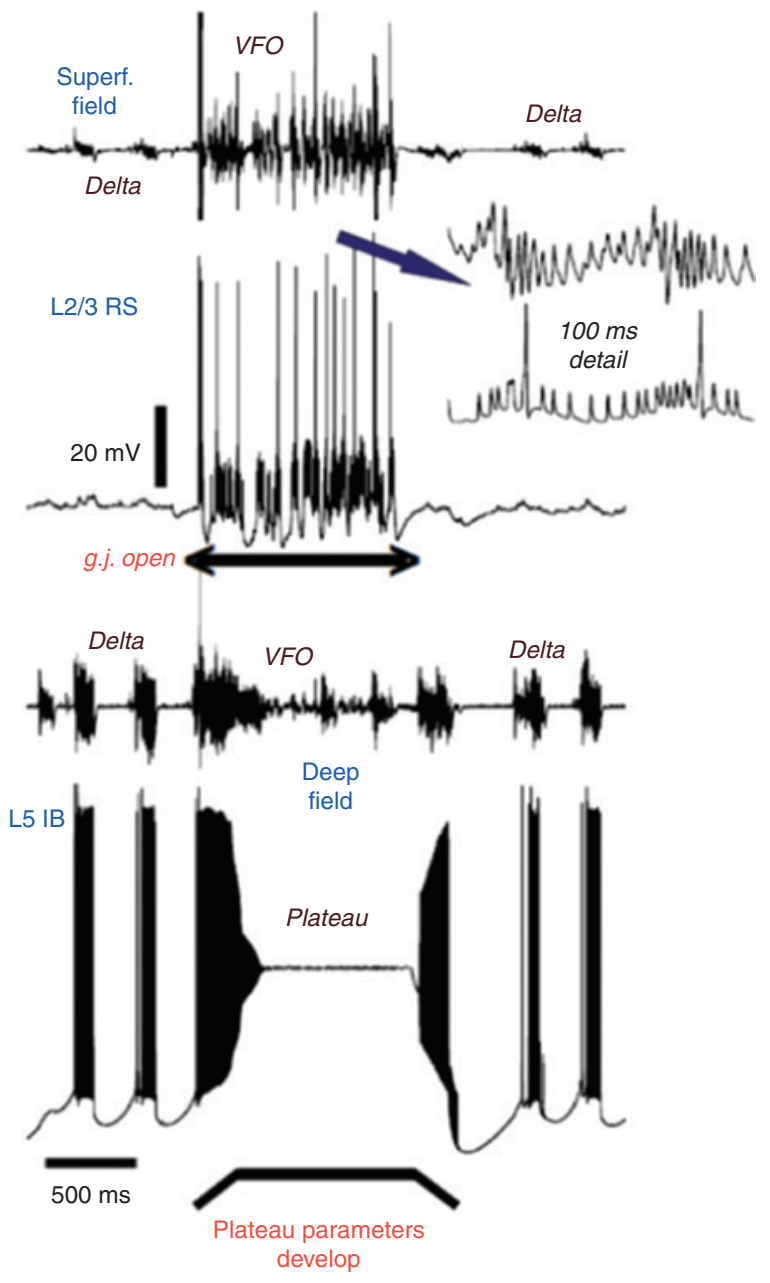

Figure 10: Simulation of IS-like EEG: delta $\rightarrow$ EEG flattening with VFO $\rightarrow$ delta.

The network model contained L5 IB pyramidal cells, tufted and nontufted deep RS pyramidal cells, superficial RS pyramidal cells, spiny stellate cells, and a variety of deep and superficial interneurons (see Methods). Background activity consisted of delta generated by L5 IB neurons and recurrent $\mathrm{GABA}_{\mathrm{B}}$ receptormediated synaptic currents, as in Hall et al., 2018. In the middle of the simulation, plateaus were induced in $\mathrm{L} 5 \mathrm{IB}$ neurons by suppressing $\mathrm{K}^{+}$currents (including $\mathrm{GABA}_{\mathrm{B}}$ mediated) and enhancing the conductance of L-type $\mathrm{Ca}^{2+}$ channels: the plateaus led to the suppression of delta as expected. Simultaneous with the plateau, gap junction conductances were enhanced between superficial pyramidal neurons, leading to superficial VFO. R.D. Traub, S.P. Hall, and M.A. Whittington, unpublished data.

reverted afterward back to delta. Thus, the overall qualitative behavior resembles what might occur with an ED response in hypsarrhythmia/IS, if we assume that patient hypsarrhythmia has similar cellular mechanisms to our in vitro delta model.

The critical notion here is that the plateau-generating factors (here, alterations in $\mathrm{GABA}_{\mathrm{B}}, \mathrm{K}^{+}$, and L-type $\mathrm{Ca}^{2+}$ conductances) and the gap junction opening factors 


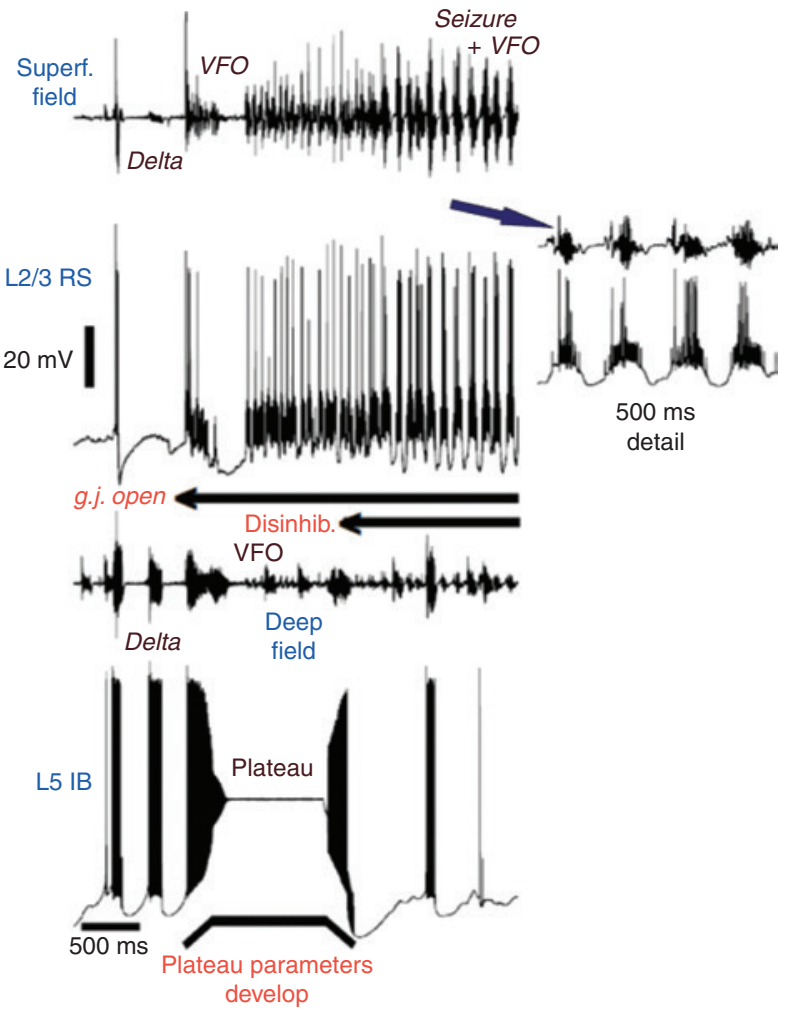

Figure 11: Simulation of in vitro behavior resembling focal seizure initiation in FCD or TS: delta $\rightarrow$ EEG flattening with delta $\rightarrow$ electrographic seizure.

The simulation of Figure 9 was repeated, but in this case (A) once superficial gap junctions were opened, they stayed opened and (B) disinhibition was introduced in superficial layers. VFO occurs as before but is transient and evolves into seizure activity that is primarily superficial. R.D. Traub, S.P. Hall, M.A. Whittington, unpublished data.

should be 'temporally correlated'. That notion, if valid, then focuses attention on those tissue properties that could both help induce a plateau and also simultaneously increase gap junction conductances. As we discuss further on, alkalinizing $\mathrm{pH}$ is one such factor.

Synthesis II: Focal seizure case: Simulation (Figure 11) shows how, in a case similar to Synthesis I, if gap junctions remain open and disinhibition develops in superficial layers, then the ED transforms into electrographic seizure

The simulation illustrated in Figure 11 was the same as for Figure 10, except that once superficial layer gap junction conductances were increased, they stayed increased; (as shown by the horizontal arrow) in the middle of the VFO segment, disinhibition was introduced in superficial cortical layers [i.e. $\mathrm{GABA}_{\mathrm{A}}$ receptors were blocked; note that in the biological neocortex, superficial GABAergic inhibition is regulated by VIP interneurons (Hall et al., 2015)]. In Figure 11 - in contrast to Synthesis I - the VFO is followed by rhythmic, seizure-like bursts in superficial pyramidal neurons (see inset), whereas delta in deep layers is partially disrupted. It will be important to determine experimentally how different neocortical pyramidal cell types behave during electrographic seizures - particularly whether some cell types are more prone to rhythmic bursts than other types. It is also of interest to note how much the behavior of simulated bursting neurons, as seen in the inset of Figure 11, resembles neuronal activities recorded during the putatively normal in vivo slow oscillation: an oscillation that is robust during ketamine/xylazine anesthesia in the cat (cf. Figure 7 in Steriade et al., 1993; Amzica and Steriade, 1995). That similarity implies that cortical neurons in vivo are capable of behaving as do the neurons in this simulation, but it remains to be proven that biological neurons so behave because of the same factors as are at work in the simulation.

Again in Figure 11, as in Figure 10, a main point to emphasize is the necessity of temporal correlations in those system parameters that are responsible for VFO and electrographic seizure activities together. Next, we shall consider some of the many observed cortical phenomena that might contribute to plateau generation, VFO, and electrographic seizures.

\section{Evidence supporting proposed model, and additional tests}

A number of physiological variables are important in determining the existence of an ED, a VFO, and a possible electrographic seizure; furthermore, these variables interact in complex ways, most of which are incompletely understood. Figure 12 summarizes some of the known interactions: here, we use data from the literature and from our own work. The most important (in our view) of the biological variables are the conductances of calcium channels, potassium channels, gap junction channels, and GABA-gated channels. To provide a 'key' to the figure, we use letters to refer to particular labeled interactions in Figure 12. A brief explanation of each interaction is provided below:

a. Alkaline $\mathrm{pH}$ enhances calcium conductances (Tombaugh and Somjen, 1996, 1997; Church et al., 1998).

b. Alkaline $\mathrm{pH}$ also opens at least some gap junction channels (e.g. Cx45). Cx45 mRNA is found in 


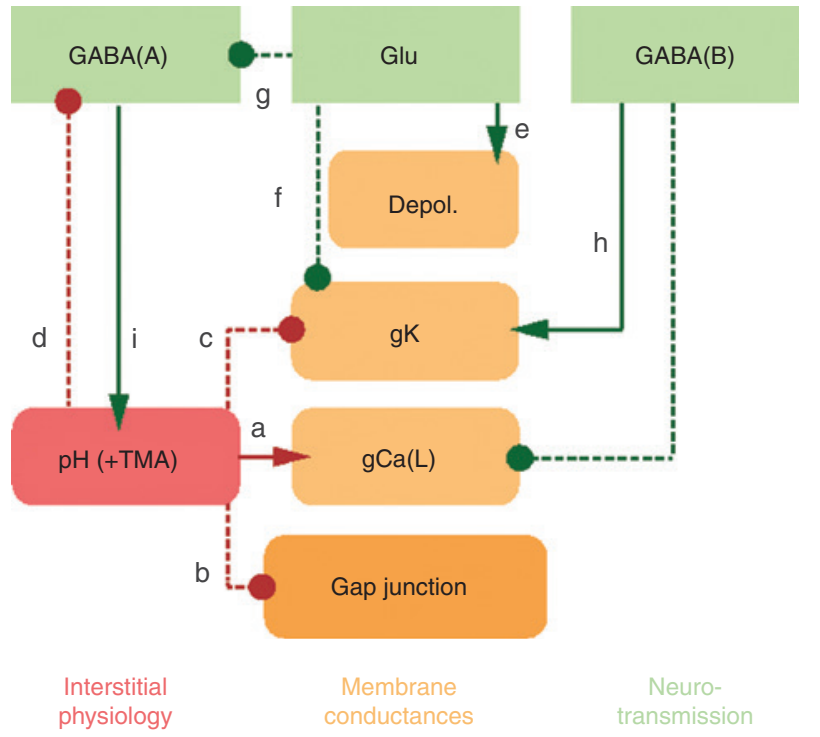

Figure 12: Some of the system interactions that could contribute to the generation of plateau potentials, VFO, and electrographic seizures.

For details, see text.

hippocampal pyramidal cells (Cembrowski et al., 2016), and Cx45 gap junction channels open at alkaline $\mathrm{pH}$ [Palacios-Prado et al., 2010; unlike Cx36 (González-Nieto et al., 2008)]. Alkaline pH increases dye coupling (putatively reflecting gap junction coupling) between hippocampal neurons (Church and Baimbridge, 1991; Perez-Velazquez et al., 1994). Alkaline $\mathrm{pH}$ also potentiates VFO and can lead to electrographic seizure activity (Traub et al., 2001, 2010). Interestingly, there is evidence that younger human pyramidal neurons have a more alkaline internal $\mathrm{pH}$ than do older neurons (Bonnet et al., 2018); this may be relevant to the occurrence of spasms in younger children. Correspondingly, at least in the mouse retina, Cx45 is widely distributed in early postnatal days but later becomes more restricted in its distribution (Kihara et al., 2006).

c. TMA, either through $\mathrm{pH}$ effects and/or direct actions on channels, blocks $\mathrm{K}^{+}$channels (Im and Quandt, 1992).

d. High $\mathrm{pH}$ artificial cerebrospinal fluid (ACSF) in vitro impairs the synaptic excitation of GABAergic neurons and also their spike initiation (Sun et al., 2012), thus producing relative disinhibition.

e. Glutamate itself can also induce a plateau if applied to apical dendrites (Schwindt and Crill, 1999). Glutamate effects are likely to be increased in alkaline conditions due to enhanced NMDA receptor responses (Makani and Chesler, 2007; not shown in Figure 12). f. Excessive glutamate release blocks $\mathrm{K}^{+}$channels (Mohapatra et al., 2009). [Sufficiently many brief depolarizations likewise lead to the cumulative inactivation of Kv2.1 channels, a subtype of $\mathrm{K}^{+}$channels (Klemic et al., 1998).]

g. Excessive glutamate can lead to the disaggregation of $\mathrm{GABA}_{\mathrm{A}}$ receptors (Bannai et al., 2015).

h. Failure of $\mathrm{GABA}_{B}$ signaling is also expected to enhance $\mathrm{Ca}^{2+}$ currents, especially in apical dendrites (i.e. in superficial neocortical layers; Chalifoux and Carter, 2011; Pérez-Garci et al., 2013; Higley, 2014; Degro et al., 2015), and also to reduce selected $\mathrm{K}^{+}$currents [Gerber and Gähwiler, 1994; Ling and Benardo, 1994; not only GIRK channels but also TEA-sensitive $\mathrm{K}^{+}$channels (Reis and Duarte, 2006)]. However, it is not clear how such failure might be coupled to $\mathrm{pH}$ changes. In contrast, glutamate (via mGluR-1 receptors) blocks one downstream target of $\mathrm{GABA}_{\mathrm{B}}$ receptors: GIRK channels (Sohn et al., 2007).

i. GABA release can elevate $\mathrm{pH}$ at least transiently (Pavlov et al., 2013; Ruusuvuori and Kaila, 2014). [The activity of pyramidal neurons also can elevate $\mathrm{pH}$ (Makani and Chesler, 2010).]

There are additional physiological factors that are also of likely relevance. First, excessive GABA release alters $\mathrm{Cl}^{-}$reversal potential and can lead to partially effective disinhibition (Pavlov et al., 2013). Second, it is possible that alkalinization increases glutamate release because of the presence of L-type calcium channels in presynaptic terminals (Tippens et al., 2008); this effect would contribute to a plateau (Schwindt and Crill, 1999). Conversely, glutamate has itself been reported to induce an alkaline transient in vitro (Paalasmaa et al., 1994). Third, alkalinization in epileptic human brain has been shown by magnetic resonance spectroscopy, although its source and properties are not known (Laxer et al., 1992). Fourth, during a plateau potential in L5 IB cells, it possible that the cells' presynaptic terminals continue to release glutamate at least until transmitter depletion occurs - assuming that the axons continue to fire action potentials even when their somata are in depolarization block. [There is some experimental evidence that axons would behave in this way (Williams and Stuart, 1999).] Finally, in other types of neurons, e.g. subthalamic neurons (Kass and Mintz, 2006) and motor neurons (Kiehn, 1991), plateau potentials may be a normal phenomenon; as far as we are aware, it is not known if plateau potentials occur normally in L5 IB neurons. Nevertheless, the occurrence of plateau potentials has been reported in rat hippocampal pyramidal cells in vitro in the presence of submicromolar 
concentrations of corticotropin-releasing hormone (CRH; see Figure 3 in Hollrigel et al., 1998). This observation is of interest in the present context, given that ACTH is used to treat IS (Riikonen, 2014) and given that systemic administration of ACTH would be expected to reduce brain CRH concentrations. It is not known, however, if the mechanism of plateau generation in the hippocampus is the same as, or similar to, the mechanism in neocortical pyramidal cells.

In summary, there are a number of interacting physiological variables that might contribute, in patients to ED responses, VFO, and seizure initiation. The first problem is to determine which of these variables are important. Based on extensive data discussed above, it is our opinion that one of the critical variables will turn out to be brain $\mathrm{pH}$. If this is the case, then the next problem is what experimental measurements can be obtained to test the idea.

Brain tissue $\mathrm{pH}$ can be measured in vivo with MRI in mice (McVicar et al., 2014) and in humans (Magnotta et al., 2012). There remains, however, a need to develop an invasive $\mathrm{pH}$ device that can be combined with ECoG, so that one can determine if brain $\mathrm{pH}$ changes are temporally correlated with (if not directly causal to) ED responses, VFO, and seizure initiation.

Another avenue to be explored concerns genetic variations in familial epilepsies, which might operate through the mechanisms we have discussed. For example, one might consider variants of the $\mathrm{Cx} 45$ gene; however, 'there is, as yet, no genetic evidence implicating variants in Cx45 in epilepsies through family studies or genome-wide association studies of singletons' (Sam Berkovic, personal communication). Nevertheless, it remains possible that Cx45 gap junction channels, as determined by normal genes, have their physiological properties modified by pathological tissue conditions - conditions that themselves are influenced by other genetic variants.

Suppose ED, VFO, and seizures really are precipitated by tissue alkalinization. Does this necessarily mean that alkalosis acts through effects on gap junction conductances or could it be through nonspecific increases in neuronal excitability? Does it matter? If preventing tissue alkalosis were to prevent seizures, that would of course be meaningful in terms of possible therapies. Even then, however, it would still be important to understand the mechanistic details, especially given the complexities of brain pH regulation (Obara et al., 2008; Ruffin et al., 2014; Ruusuvuori and Kaila, 2014). For example, gap junction conductances might be affected by smaller $\mathrm{pH}$ fluctuations than are the kinetics of voltage- or ligand-gated membrane channels. This question is experimentally addressable and could have practical consequences.

\section{Review of our three basic hypotheses}

Summarizing some the data that reflect on our starting hypotheses, we have the following conclusions:

Hypothesis 1: The neocortical ED occurs because L5 IB pyramidal neurons develop sustained depolarizing plateaus, which suppress delta and flatten the EEG. We have provided evidence above that plateaus in L5 IB pyramidal neurons would account for the disruption of delta (because delta is generated by this very cell type). It is interesting also that there is impaired glutamate transport in a mouse TS epilepsy model, an abnormality that could contribute to plateaus in L5 IB neurons (Schwindt and Crill, 1999). It would also be useful to know if depolarizing plateaus could suppress other cortical rhythms besides delta, but so far data are lacking on this issue.

Hypothesis 2: Tissue conditions (including alkaline $\mathrm{pH}$ and glutamate release), which favor the ED, also favor VFO generated by superficial pyramidal neurons. The strong effect of alkaline $\mathrm{pH}$, on eliciting VFO, has been shown specifically for neocortex L5 (Traub et al., 2010; see Figure 7). There is also evidence that a combination of glutamate release and alkalinization (from TMA) combine to produce VFO followed by an electrographic seizure in the hippocampus (Figures 8 and 9 in Traub et al., 2001); note that the tetanic stimulus used in that study has been shown to produce large slow metabotropic glutamate excitatory postsynaptic potentials (EPSPs) and must therefore involve glutamate release (Whittington et al., 1997). Glutamate release could then act as shown by Schwindt and Crill (1999).

Hypothesis 3: If, during the ED, VFO persists and sufficient superficial disinhibition develops, an electrographic seizure will occur. In the clinical situation, there is a correlation between persistent VFO and seizure occurrence, but it is not presently possible to determine directly the status of synaptic inhibition in a patient's brain. Indirect methods based on the observation of firing rates are not sufficient. This is an issue that may need to be pursued in animal models.

Spatiotemporal patterns of epileptiform activity, with varying inhibitory strengths, have been studied previously, at times with intracellular recordings, both in vivo (Prince and Wilder, 1967; Dichter and Spencer, 1969; Bink et al., 2018) and in vitro (Miles and Wong, 1987); often, pharmacological disinhibition is used. The situation we are proposing based on specifically superficial disinhibition (Hall et al., 2015, 2018) is, however, somewhat distinct.

\section{Clinical significance: Part 1: carbonic anhydrase inhibiting anticonvulsant drugs}

A major theme of this review has been the possible role of alkaline brain $\mathrm{pH}$ in facilitating both neuronal plateaus 
and also VFO. If correct, this would be clinically important, because a number of anticonvulsant drugs exhibit carbonic anhydrase inhibiting activity, for example, acetazolamide, topiramate, and zonisamide (Aggarwal et al., 2013), although the actions on carbonic anhydrase may or may not be relevant to the antiepileptic effects. Drugs of this type would be expected to acidify the brain; it would be helpful to have experiments showing this directly. Experiments that examine the actions of carbonic anhydrase inhibitors on VFO in vitro would also be useful, especially experiments employing different VFO induction protocols. Brain acidification might also be an important mechanism in the actions of the ketogenic diet, although, to the best of our knowledge, this remains to be proven. [In contrast to actions on $\mathrm{pH}$, vigabatrin, an inhibitor of GABA transaminase (Petroff and Rothman, 1998) that can be effective against IS (Song et al., 2017), probably acts differently: it enhances the coactivation of both $\mathrm{GABA}_{\mathrm{A}}$ and $\mathrm{GABA}_{\mathrm{B}}$ receptors via synaptically released GABA (Costa et al., 2004), and the actions on $\mathrm{GABA}_{\mathrm{B}}$ receptors would be expected to diminish the chances of pyramidal cell plateaus and the ED response.]

To pursue these ideas, we see a pressing need for a technology that would safely allow the measurement of intracranial EEG and brain $\mathrm{pH}$ simultaneously. If such a technology is feasible, then the resulting measurements could prove or disprove the notion that brain alkalinization actually does contribute to ED responses, VFO, and seizure initiation.

Additionally, work is in progress to develop means of delivering drugs through the blood-brain barrier and then specifically to (for example) neurons or astrocytes directly (Zhang et al., 2016; Madhusudanan et al., 2017). If further studies support the $\mathrm{pH}$ mechanisms we propose, then it may eventually be possible to deliver carbonic anhydrase inhibitors to neurons and/or astrocytes directly, thus avoiding side effects of the systemically administered drugs, for example, urolithiasis (Hamed, 2017).

\section{Clinical significance: Part 2: other neurological conditions with EEG flattening}

If it is indeed true that plateaus in L5 IB pyramidal neurons account for EDs in IS and focal seizure initiation, then it may be the case that plateaus in L 5 neurons also account for (relative) EEG flattenings in diverse other conditions. Important examples include the periodic or quasiperiodic cortical electrical signals often recorded in herpes simplex encephalitis (Smith et al., 1975), subacute sclerosing panencephalitis (Westmoreland et al., 1976), and CreutzfeldtJakob disease (Chiofalo et al., 1980). Additionally, one should consider burst suppression EEGs and prolonged electrical silence as can be seen in Ohtahara syndrome (Clarke et al., 1987; Backx et al., 2009), deep general anesthesia (Lewis et al., 2013), or hypothermia (Hicks and Poole, 1981). It is especially interesting that burst suppression can also be associated with VFO, a finding compatible with the notion that hypsarrhythmia and burst suppression may lie on a spectrum of brain network behaviors; that notion is supported by the observation that hypsarrhythmia and burst suppression can occur in the same patient (Kramer et al., 1997; Korff et al., 2012). Some of the aforementioned conditions, such as general anesthesia, should be experimentally addressable with animal models. Notably, based on cat models of burst suppression, Steriade et al. (1994) and Kroeger et al. (2013) have emphasized the hyperexcitability present in this state.

Given that plateau potentials in pyramidal neurons are driven at least in part by enhanced calcium conductances, this raises the concern that plateau potentials (especially sustained ones) might lead to the death of L5 IB neurons because of excessive $\mathrm{Ca}^{2+}$ entry (Siesjö, 1989). We raise the possibility that this mechanism could contribute to the morbidity and mortality sometimes associated with conditions in which EEG EDs or EEG periodicities occur. If evidence supports this notion, it suggests that $\mathrm{Ca}^{2+}$ channel blockers might be of prophylactic benefit in such conditions.

Acknowledgments: This study was funded by IBM Corp. and NINDS/NIH NS044133 (R.D.T.; from the National Institute of Neurological Diseases and Stroke/National Institutes of Health); Wellcome Trust Funder Id: http://dx.doi. org/10.13039/100004440, 209164/Z/17/Z (M.A.W. and S.P.H.); with infrastructure support through the National Institute for Health Research Biomedical Research Centre at Great Ormond Street Hospital for Children, NHS Foundation Trust and University College London (R.R.); and Great Ormond Street Hospital Children's Charity (T.B.). We acknowledge the helpful discussions with Drs. Yoshio Okada, Sufi Zafar, Sam Berkovic, David Grayden, and Mark Cook. We thank Drs. Joefon Jann and Robert Walkup (IBM Corp.) for the invaluable computing support.

\section{Appendix: Methods}

\section{Clinical intracranial SEEG recordings}

Intracranial EEG data recorded here were routine clinical recordings performed as part of the comprehensive 
pediatric epilepsy surgery program at Great Ormond Street Hospital (London, UK) and were conducted entirely based on clinical need. SEEG was recorded via depth electrodes placed in the brain parenchyma through burr holes placed to record electrical activity from the epileptogenic network during telemetry in hospital stay. Recordings were performed at sampling frequencies of $1 \mathrm{kHz}$ and displayed in bipolar reference for visualization purposes. The use of anonymized SEEG data for research purposes was reviewed and approved by the UK National Health Regulatory Authority and the local hospital research and development office.

\section{In vitro methods}

Coronal slices ( $450 \mu \mathrm{m}$ thick) containing secondary somatosensory/parietal area S2/Par2 were prepared from adult male Wistar rats $(\sim 150 \mathrm{~g})$ and maintained at $34^{\circ} \mathrm{C}$ at the interface between humidified $95 \% \mathrm{O}_{2} / 5 \%$ $\mathrm{CO}_{2}$ and ACSF containing $126 \mathrm{~mm} \mathrm{NaCl}, 3 \mathrm{~mm} \mathrm{KCl}$, $1.25 \mathrm{~mm} \mathrm{NaH}_{2} \mathrm{PO}_{4}, 1 \mathrm{mM} \mathrm{MgSO}_{4}, 1.2 \mathrm{~mm} \mathrm{CaCl}_{2}, 24 \mathrm{~mm}$ $\mathrm{NaHCO}_{3}$ and $10 \mathrm{~mm}$ glucose. All surgical procedures were in accordance with the regulations of the UK Animals (Scientific Procedures) Act of 1986. Persistent, spontaneous delta rhythms were induced by perfusion of the cholinergic agonist carbachol $(2 \mu \mathrm{M})$ and the D1 dopamine receptor antagonist SCH23390 $(10 \mu \mathrm{M})$ according to the methods of Carracedo et al. (2013). Delta-based epileptiform activity was generated by bath application of TMA (1 $\mathrm{mm})$ to alkalinize neuronal cytosol and dTC $(10 \mu \mathrm{M})$ to selectively reduce superficial layer inhibition (Hall et al., 2015). Extracellular field potential recordings were taken with micropipettes (2-5 M $\Omega$ ) filled with ACSF. Intracellular recordings used pipettes with $2 \mathrm{M}$ potassium acetate (50-100 M $\Omega$ ). Extracellular data were bandpass filtered at $0.1 \mathrm{~Hz}$ to $0.5 \mathrm{kHz}$, with intracellular DC recordings low-passed filtered at $2.5 \mathrm{kHz}$.

\section{Model structure}

The simulation program used was called plateauVFO.f, written in Fortran to run on 10 processors in the mpi parallel environment, Linux operating system. The processors resided in a Power8 chip in the Cognitive Computing Cluster at the IBM Thomas J. Watson Research Center. The structure of the program was similar to that of spikewaveS.f used by Hall et al. (2018), with these modifications:
1. Deep-layer low-threshold spiking (LTS) interneurons were removed; instead, there were VIP interneurons (see Hall et al., 2018), which produce $\mathrm{GABA}_{\mathrm{A}}$ receptormediated inhibitory postsynaptic potentials (IPSPs) in various interneuron types, and small $\mathrm{GABA}_{A}$ and $\mathrm{GABA}_{\mathrm{B}}$ receptor-mediated IPSPs in pyramidal cell dendrites in the superficial cortical layers.

2. The numbers of neurons of different types were adjusted so that the program would run on 10 processors for computational efficiency. The neurons are superficial interneurons (100 basket, 100 axoaxonic, 100 LTS, 100 VIP, and 100 neurogliaform), deep interneurons (200 basket, 100 axoaxonic, and 200 neurogliaform), spiny stellate (500), nontufted deep pyramids (500), RS tufted deep pyramids (500), IB deep pyramids (500), and superficial RS pyramids (1000). As before, neurogliaform interneurons produce $\mathrm{GABA}_{\mathrm{A}}$ and $\mathrm{GABA}_{\mathrm{B}}$ receptor-mediated IPSPs.

3. The code was added to allow for time-dependent alterations in membrane conductance densities (intrinsic and/or synaptic) of IB pyramidal cells; this was done to explore the conditions that result in plateau potentials. For the details of the alterations used here, see Figures 10 and 11.

The source code can be obtained from rtraub@us.ibm. com (and will be deposited in ModelDB.

\section{References}

Aggarwal, M., Kondeti, B., and McKenna, R. (2013). Anticonvulsant/ antiepileptic carbonic anhydrase inhibitors: a patent review. Expert Opin. Ther. Pat. 23, 717-724.

Akiyama, T., Otsubo, H., Ochi, A., Ishiguro, T., Kadokura, G., Nair, R.R., Weiss, S.K., Rutka, J.T., and Snead 3rd, O.C. (2005). Focal cortical high-frequency oscillations trigger epileptic spasms: confirmation by digital video subdural EEG. Clin. Neurophysiol. 116, 2819-2825.

Amzica, F. and Steriade, M. (1995). Short- and long-range neuronal synchronization of the slow $(<1 \mathrm{~Hz})$ cortical oscillation. J. Neurophysiol. 73, 20-38.

André, V.M., Flores-Hernández, J., Cepeda, C., Starling, A.J., Nguyen, S., Lobo, M.K., Vinters, H.V., Levine, M.S., and Mathern, G.W. (2004). NMDA receptor alterations in neurons from pediatric cortical dysplasia tissue. Cereb. Cortex 14, 634-646.

Apostolides, P.F., Milstein, A.D., Grienberger, C., Bittner, K.C., and Magee, J.C. (2016). Axonal filtering allows reliable output during dendritic plateau-driven complex spiking in CA1 neurons. Neuron 89, 770-783.

Arroyo, S., Lesser, R.P., Fisher, R.S., Vining, E.P., Krauss, G.L., Bandeen-Roche, K., Hart, J., Gordon, B., Uematsu, S., and Webber, R. (1994). Clinical and electroencephalographic evidence 
for sites of origin of seizures with diffuse electrodecremental pattern. Epilepsia 35, 974-987.

Backx, L., Ceulemans, B., Vermeesch, J.R., Devriendt, K., and Van Esch, H. (2009). Early myoclonic encephalopathy caused by a disruption of the neuregulin-1 receptor ErbB4. Eur. J. Hum. Genet. 17, 378-382.

Bannai, H., Niwa, F., Sherwood, M.W., Shrivastava, A.N., Arizono, M., Miyamoto, A., Sugiura, K., Lévi, S., Triller, A., and Mikoshiba, K. (2015). Bidirectional control of synaptic $G A B A_{A} R$ clustering by glutamate and calcium. Cell Rep. 13, 2768-2780.

Bink, H., Sedigh-Sarvestani, M., Fernandez-Lamo, I., Kini, L., Ung, H., Kuzum, D., Vitale, F., Litt, B., and Contreras, D. (2018). Spatiotemporal evolution of focal epileptiform activity from surface and laminar field recordings in cat neocortex. J. Neurophysiol. 119, 2068-2081.

Bonaiuto, J., Rossiter, H.E., Meyer, S.S., Adams, N., Little, S., Callaghan, M.F., Dick, F., Bestmann, S., and Barnes, G.R. (2018). Noninvasive laminar inference with MEG: comparison of methods and source inversion algorithms. Neuroimage 167, 372-383.

Bonnet, U., Bingmann, D., Speckmann, E.J., and Wiemann, M. (2018). Aging is associated with a mild acidification in neocortical human neurons in vitro. J. Neural Transm. 125, 1495-1501.

Boto, E., Holmes, N., Leggett, J., Roberts, G., Shah, V., Meyer, S.S., Muñoz, L.D., Mullinger, K.J., Tierney, T.M., Bestmann, S., et al. (2018). Moving magnetoencephalography towards real-world applications with a wearable system. Nature 555, 657-661.

Buhl, D.L., Harris, K.D., Hormuzdi, S.G., Monyer, H., and Buzsáki, G. (2003). Selective impairment of hippocampal gamma oscillations in connexin-36 knock-out mouse in vivo. J. Neurosci. 23, 1013-1018.

Caraballo, R.H., Reyes, G., Falsaperta, R., Ramos, B., Ruiz, A.C., Fernandez, C.A., Peretti, G., and Beltran, L. (2016). Epileptic spasms in clusters with focal EEG paroxysms: a study of 12 patients. Seizure 35, 88-92.

Carracedo, L.M., Kjeldsen, H., Cunnington, L., Jenkins, A., Schofield, I., Cunningham, M.O., Traub, R.D., and Whittington, M.A. (2013). A neocortical delta rhythm facilitates reciprocal interlaminar interactions via nested theta rhythms. J. Neurosci. 33, 10750-10761.

Cembrowski, M.S., Wang, L., Sugino, K., Shields, B.C., and Spruston, N. (2016). Hipposeq: a comprehensive RNA-seq database of gene expression in hippocampal principal neurons. eLife 5, e14997.

Cepeda, C., André, V.M., Levine, M.S., Salamon, N., Miyata, H., Vinters, H.V., and Mathern, G.W. (2006). Epileptogenesis in pediatric cortical dysplasia: the dysmature cerebral developmental hypothesis. Epilepsy Behav. 9, 219-235.

Cepeda, C., André, V.M., Wu, N., Yamazaki, I., Uzqil, B., Vinters, H.V., Levine, M.S., and Mathern, G.W. (2007). Immature neurons and GABA networks may contribute to epileptogenesis in pediatric cortical dysplasia. Epilepsia 48, 79-85.

Chalifoux, J.R. and Carter, A.G. (2011). GABA $\mathrm{B}_{\mathrm{B}}$ receptor modulation of voltage-sensitive calcium channels in spines and dendrites. J. Neurosci. 31, 4221-4232.

Chiofalo, N., Fuentes, A., and Gálvez, S. (1980). Serial EEG findings in 27 cases of Creutzfeldt-Jakob disease. Arch. Neurol. 37, 143-145.

Church, J. and Baimbridge, K.G. (1991). Exposure to high-pH medium increases the incidence and extent of dye coupling between rat hippocampal CA1 pyramidal neurons in vitro. J. Neurosci. 11, 3289-3295.
Church, J., Baxter, K.A., and McLarnon, J.G. (1998). pH modulation of $\mathrm{Ca}^{2+}$ responses and a $\mathrm{Ca}^{2+}$-dependent $\mathrm{K}^{+}$channel in cultured rat hippocampal neurones. J. Physiol. 511, 119-132.

Clarke, M., Gill, J., Noronha, M., and McKinlay, I. (1987). Early infantile epileptic encephalopathy with suppression burst: Ohtahara syndrome. Dev. Med. Child Neurol. 29, 520-528.

Colquhoun, D., Jonas, P., and Sakmann, B. (1992). Action of brief pulses of glutamate on AMPA/kainate receptors in patches from different neurons of rat hippocampal slices. J. Physiol. 458, 261-287.

Costa, C., Leone, G., Saulle, E., Pisani, F., Bernardi, G., and Calabresi, P. (2004). Coactivation of $G A B A_{A}$ and $G A B A_{B}$ receptor results in neuroprotection during in vitro ischemia. Stroke 35 , 596-600.

Crino, P.B. (2015). mTOR signalling in epilepsy: insights from malformations of cortical development. Cold Spring Harb. Perspect. Med. 5, a022442.

Cunningham, M.O., Whittington, M.A., Bibbig, A., Roopun, A., LeBeau, F.E.N., Vogt, A., Monyer, H., Buhl, E.H., and Traub, R.D. (2004). A role for fast rhythmic bursting neurons in cortical gamma oscillations in vitro. Proc. Natl. Acad. Sci. U.S.A. 101, 7152-7157.

Cunningham, M.O., Roopun, A.K., Schofield, I.S., Whittaker, R.G., Duncan, R., Russell, A., Jenkins, A., Nicholson, C., Whittington, M.A., and Traub, R.D. (2012). Glissandi: transient fast electrocorticographic oscillation of steadily increasing frequency, explained by temporally increasing gap junction conductance. Epilepsia 53, 1205-1214.

Curatolo, P., Seri, S., Verdecchia, M., and Bombardieri, R. (2001). Infantile spasms in tuberous sclerosis complex. Brain Dev. 23, 502-507.

Daniels, D., Knupp, K., Benke, T., Wolter-Warmerdam, K., Moran, M., and Hickey, F. (2019). Infantile spasms in children with Down syndrome: identification and treatment response. Glob. Pediatr. Health 6, 2333794 X18821939.

Davidson, J.S., Baumgarten, I.M., and Harley, E.H. (1986). Reversible inhibition of intercellular junctional communication by glycyrrhetinic acid. Biochem. Biophys. Res. Commun. 134, 29-36.

Degro, C.E., Kulik, A., Booker, S.A., and Vida, I. (2015). Compartmental distribution of $\mathrm{GABA}_{B}$ receptor-mediated currents along the somatodendritic axis of hippocampal pyramidal cells. Front. Synaptic Neurosci. 7, 6.

Dichter, M. and Spencer, W.A. (1969). Penicillin-induced interictal discharges from the cat hippocampus. II. Mechanisms underlying origin and restriction. J. Neurophysiol. 32, 663-687.

Draguhn, A., Traub, R.D., Schmitz, D., and Jefferys, J.G.R. (1998). Electrical coupling underlies high-frequency oscillations in the hippocampus in vitro. Nature 394, 189-192.

French, R.J. and Shoukimas, J.J. (1981). Blockage of squid axon potassium conductance by internal tetra- $\mathrm{N}$-alkylammonium ions of various sizes. Biophys. J. 34, 271-291.

Fu, C., Cawthon, B., Clinkscales, W., Bruce, A., Winzenburger, P., and Ess, K.C. (2012). GABAergic interneuron development and function is modulated by the Tsc1 gene. Cereb. Cortex 22, 2111-2119.

Fujiwara, H., Leach, J.L., Greiner, H.M., Holland-Bouley, K.D., Rose, D.F., Arthur, T., and Mangano, F.T. (2016). Resection of ictal high frequency oscillations is associated with favourable surgical outcome in pediatric drug resistant epilepsy secondary to tuberous sclerosis complex. Epilepsy Res. 126, 90-97. 
Gerber, U. and Gähwiler, B.H. (1994). GABA and adenosine receptors mediate enhancement of the $\mathrm{K}^{+}$current, $\mathrm{I}_{\text {AHP }}$, by reducing adenylyl cyclase activity in rat CA3 hippocampal neurons. J. Neurophysiol. 72, 2360-2367.

González-Nieto, D., Gómez-Hernández, J.M., Larrosa, B., Gutiérrez, C., Muñoz, M.D., Fasciani, I., O’Brien, J.O., Zappalà, A., Cicirata, F., and Barrio, L.C. (2008). Regulation of neuronal connexin-36 channels by pH. Proc. Natl. Acad. Sci. U.S.A. 105, 17169-17174.

Grenier, F., Timofeev, I., and Steriade, M. (2003). Neocortical very fast oscillations (ripples, $80-200 \mathrm{~Hz}$ ) during seizures: intracellular correlates. J. Neurophysiol. 89, 841-852.

Grinenko, O., Li, J., Mosher, J.C., Wang, I.Z., Bulacio, J.C., GonzalezMartinez, J., Nair, D., Najm, I., Leahy, R.M., and Chauvel, P. (2018). A fingerprint of the epileptogenic zone in human epilepsies. Brain 141, 117-131.

Hall, S., Hunt, M., Simon, A., Cunnington, L.G., Schofield, I.S., Traub, R.D., and Whittington, M.A. (2015). Unbalanced peptidergic inhibition in superficial neocortex generates sleep-associated seizure activity. J. Neurosci. 35, 9302-9314.

Hall, S., Traub, R.D., Adams, N.E., Cunningham, M.O., Schofield, I., Jenkins, A., and Whittington, M.S. (2018). Enhanced interlaminar excitation or reduced superficial layer inhibition in neocortex generates different spike and wave-like electrographic events in vitro. J. Neurophysiol. 119, 49-61.

Hamed, S.A. (2017). The effect of antiepileptic drugs on the kidney function and structure. Expert Rev. Clin. Pharmacol. 10, 993-1006.

Herbst, S.M., Proepper, C.R., Geis, T., Borggraefe, I., Hahn, A., Debus, O., Haeussler, M., von Gersdorff, G., Kurlemann, G., Ensslen, M., et al. (2016). LIS1-associated classic lissencephaly: a retrospective, multicenter survey of the epileptogenic phenotype and response to antiepileptic drugs. Brain Dev. 38, 399-406.

Hicks, R.G. and Poole, J.L. (1981). Electroencephalographic changes with hypothermia and cardiopulmonary bypass in children. J. Thorac. Cardiovasc. Surg. 81, 781-786.

Higley, M.J. (2014). Localized GABAergic inhibition of dendritic $\mathrm{Ca}^{2+}$ signaling. Nat. Rev. Neurosci. 15, 567-572.

Hollrigel, G.S., Chen, K., Baram, T.Z., and Soltesz, I. (1998). The proconvulsant actions of corticotropin-releasing hormone in the hippocampus of infant rats. Neuroscience 84, 71-79.

Hrachovy, R.A. and Frost Jr., J.D. (2003). Infantile epileptic encephalopathy with hypsarrhythmia (infantile spasms/West syndrome). J. Clin. Neurophysiol. 20, 408-425.

Hrachovy, R.A. and Frost Jr., J.D. (2013). Infantile spasms. Handb. Clin. Neurol. 111, 611-618.

Im, W.B. and Quandt, F.N. (1992). Mechanism of asymmetric block of $\mathrm{K}$ channels by tetraalkylammonium ions in mouse neuroblastoma cells. J. Membr. Biol. 130, 115-124.

Inoue, T., Kobayashi, K., Oka, M., Yoshinaga, H., and Ohtsuka, Y. (2008). Spectral characteristics of EEG gamma rhythms associated with epileptic spasms. Brain Dev. 30, 321-328.

Inoue, T., Shimizu, M., Hamano, S., Murakami, N., Nagai, T., and Sakuta, R. (2014). Epilepsy and West syndrome in neonates with hypoxic-ischemic encephalopathy. Pediatr. Int. 56, 369-372.

Jdila, M.B., Issa, A.B., Khabou, B., Rhouma, B.B., Kamoun, F., Ammar-Keskes, L., Triki, C., and Fakhfakh, F. (2017). Novel mutations in the CKDL5 gene in complex genotypes associated with West syndrome with variable phenotype: first description of somatic mosaic state. Clin. Chim. Acta 473, 51-59.
Kannan, L., Vogrin, S., Bailey, C., Maxiner, W., and Harvey, A.S. (2016). Centre of epileptogenic tubers generate and propagate seizures in tuberous sclerosis. Brain 139, 2653-2667.

Kass, J.I. and Mintz, I.M. (2006). Silent plateau potentials, rhythmic bursts, and pacemaker firing: three patterns of activity that coexist in quadristable subthalamic neurons. Proc. Natl. Acad. Sci. U.S.A. 103, 183-188.

Kiehn, O. (1991). Plateau potentials and active integration in the 'final common pathway' for motor behavior. Trends Neurosci. $14,68-73$.

Kihara, A.H., Mantovani de Castro, L., Belmonte, M.A., Moriscot, A.S., and Hamassaki, D.E. (2006). Expression of connexins 36, 43 , and 45 during postnatal development of the mouse retina. J. Neurobiol. 66, 1397-1410.

Kim, M.-J., Yum, M.-S., Yeh, H.-R., and Ko, T.-S. (2018). Fast oscillation dynamics during hypsarrhythmia as a localization biomarker. J. Neurophys. 119, 679-687.

Klemic, K.G., Shieh, C.C., Kirsch, G.E., and Jones, S.W. (1998). Inactivation of Kv2.1 potassium channels. Biophys. J. 74, 1779-1789.

Kobayashi, K., Oka, M., Akiyama, T., Inoue, T., Abiru, K., Ogino, T., Yoshinaga, H., Ohtsuka, Y., and Oka, E. (2004). Very fast rhythmic activity on scalp EEG associated with epileptic spasms. Epilepsia 45, 488-496.

Kobayashi, K., Akiyama, T., Oka, M., Endoh, F., and Yoshinaga, H. (2015). A storm of fast (40-150 Hz) oscillations during hypsarrhythmia in West syndrome. Ann. Neurol. 77, 58-67.

Korff, C.M., Vulliemoz, S., Picard, F., and Fluss, J. (2012). Ohtahara syndrome or early-onset West syndrome? A case with overlapping features and favorable response to vigabatrin. Eur. J. Paed. Neurol. 16, 753-757.

Kossoff, E.H. (2010). Infantile spasms. Neurologist 16, 69-75.

Kramer, U., Sue, W.C., and Mikati, M.A. (1997). Hypsarrhythmia: frequency of variant patterns and correlation with etiology and outcome. Neurology 48, 197-203.

Kroeger, D., Florea, B., and Amzica, F. (2013). Human brain activity patterns beyond the isoelectric line of extreme deep coma. PLoS One 8, e75257.

Laxer, K.D., Hubesch, B., Sappey-Marinier, D., and Weiner, M.W. (1992). Increased pH and inorganic phosphate in temporal seizure foci demonstrated by [ $\left.{ }^{31} \mathrm{P}\right]$ MRS. Epilepsia 33, 618-623.

Lemke, J.R., Hendrickx, R., Geider, K., Laube, B., Schwake, M., Harvey, R.J., James, V.M., Pepler, A., Steiner, I., Hörtnagel, K., et al. (2014). GRIN2B mutations in West syndrome and intellectual disability with focal epilepsy. Ann Neurol. 75, 147-154.

Lewis, L.D., Ching, S., Weiner, V.S., Peterfreund, R.A., Eskandar, E.N., Cash, S.S., Brown, E.N., and Purdon, P.L. (2013). Local cortical dynamics of burst suppression in the anaesthetized brain. Brain 136, 2727-2737.

Li, T., Cheng, M., Wang, J., Hong, S., Li, M., Liao, S., Xie, L., and Jiang, L. (2018). De novo mutations of STXBP1 in Chinese children with early onset epileptic encephalopathy. Genes Brain Behav. 17, e12492.

Ling, D.S. and Benardo, L.S. (1994). Properties of isolated GABA ${ }_{B}$ mediated inhibitory postsynaptic currents in hippocampal pyramidal cells. Neuroscience 63, 937-944.

Madhusudanan, P., Reade, S., and Shankarappa, S.A. (2017). Neuroglia as targets for drug delivery systems: a review. Nanomedicine 13, 667-679.

Magnotta, V.A., Heo, H.-Y., Dlouhy, B.J., Dahdaleh, N.S., Follmer, R.L., Thedens, D.R., Welsh, M.J., and Wemmie, J.A. (2012). 
Detecting activity-evoked $\mathrm{pH}$ changes in human brain. Proc. Natl. Acad. Sci. U.S.A. 109, 8270-8273.

Major, P., Rakowski, S., Simon, M.V., Cheng, M.L., Eskandar, E., Baron, J., Leeman, B.A., Frosch, M.P., and Thiele, E.A. (2009). Are cortical tubers epileptogenic? Evidence from electrocorticography. Epilepsia 50, 147-154.

Makani, S. and Chesler, M. (2007). Endogenous alkaline transients boost postsynaptic NMDA receptor responses in hippocampal CA1 pyramidal neurons. J. Neurosci. 27, 7438-7446.

Makani, S. and Chesler, M. (2010). Rapid rise of extracellular pH evoked by neural activity is generated by the plasma membrane calcium ATPase. J. Neurophysiol. 103, 667-676.

Marcotte, L., Aronica, E., Baybis, M., and Crino, P.B. (2012). Cytoarchitectural alterations are widespread in cerebral cortex in tuberous sclerosis complex. Acta Neuropathol. 123, 685-693.

McVicar, N., Li, A.X., Gonçalves, D.F., Bellyou, M., Meakin, S.O., Prado, M.A., and Bartha, R. (2014). Quantitative tissue pH measurement during cerebral ischemia using amine and amide concentration-independent detection (AACID) with MRI. J. Cereb. Blood Flow Metab. 34, 690-698.

Mercer, A., Bannister, A.P., and Thomson, A.M. (2006). Electrical coupling between pyramidal cells in adult cortical regions. Brain Cell Biol. 35, 13-27.

Miles, R. and Wong, R.K.S. (1987). Inhibitory control of local excitatory circuits in the guinea-pig hippocampus. J. Physiol. 388, 611-629.

Mohamed, A.R., Bailey, C.A., Freeman, J.L., Maixner, W., Jackson, G.D., and Harvey, A.S. (2012). Intrinsic epileptogenicity of cortical tubers revealed by intracranial EEG monitoring. Neurology 79, 2249-2257.

Mohapatra, D.P., Misonou, H., Pan, S.J., Held, J.E., Surmeier, D.J., and Trimmer, J.S. (2009). Regulation of intrinsic excitability in hippocampal neurons by activity-dependent modulation of the KV2.1 potassium channel. Channels 3, 46-56.

Obara, M., Szeliga, M., and Albrecht, J. (2008). Regulation of pH in the mammalian central nervous system under normal and pathological conditions: facts and hypotheses. Neurochem. Int. 52, 905-919.

Ogawa, T., Sugiyama, A., Ishiwa, S., Suzuki, M., Ishihara, T., and Sato, K. (1984). Ontogenetic development of autoregressive component waves of waking EEG in normal infants and children. Brain Dev. 6, 289-303.

Ohtahara, S. and Yamatogi, Y. (2003). Epileptic encephalopathies in early infancy with suppression-burst. J. Clin. Neurophysiol. 20, 398-407.

Oka, M., Kobayashi, K., Akiyama, T., Ogino, T., and Oka, E. (2004). A study of spike-density on EEG in West syndrome. Brain Dev. 26, 105-112.

Olbrich, E., Rusterholz, T., LeBourgeois, M.K., and Achermann, P. (2017). Developmental changes in sleep oscillations during early childhood. Neural Plast. 6160959.

Paalasmaa, P., Taira, T., Voipio, J., and Kaila, K. (1994). Extracellular alkaline transients mediated by glutamate receptors in the rat hippocampal slice are not due to a proton conductance. J. Neurophysiol. 72, 2031-2013.

Palacios-Prado, N., Briggs, S.W., Skeberdis, V.A., Pranevicius, M., Bennett, M.V., and Bukauskas, F.F. (2010). pH-dependent modulation of voltage gating in connexin 45 homotypic and connexin45/connexin43 heterotypic gap junctions. Proc. Natl. Acad. Sci. U.S.A. 107, 9897-9902.
Pavlov, I., Kaila, K., Kullmann, D.M., and Miles, R. (2013). Cortical inhibition, $\mathrm{pH}$ and cell excitability in epilepsy: what are optimal targets for antiepileptic interventions? J. Physiol. 591, 765-774.

Pérez-Garci, E., Larkum, M.E., and Nevian, T. (2013). Inhibition of dendritic $\mathrm{Ca}^{2+}$ spikes by $\mathrm{GABA}_{\mathrm{B}}$ receptors in cortical pyramidal neurons is mediated by a direct $\mathrm{G}_{\mathrm{i} / 0}-\beta \gamma$-subunit interaction with $\mathrm{Ca}_{\mathrm{v}} 1$ channels. J. Physiol. 591, 1599-1612.

Perez-Velazquez, J.L., Valiante, T.A., and Carlen, P.L. (1994). Modulation of gap junctional mechanisms during calcium-free induced field burst activity: a possible role for electrotonic coupling in epileptogenesis. J. Neurosci. 14, 4308-4317.

Perucca, P., Dubeau, F., and Gotman, J. (2014). Intracranial electroencephalographic seizure-onset patterns: effect of underlying pathology. Brain 137, 183-196.

Petroff, O.A. and Rothman, D.L. (1998). Measuring human brain GABA in vivo: effects of GABA-transaminase inhibition with vigabatrin. Mol. Neurobiol. 16, 97-121.

Prince, D.A. and Wilder, B.J. (1967). Control mechanisms in cortical epileptogenic foci. 'Surround' inhibition. Arch. Neurol. 16, 194-202.

Ramachandrannair, R., Ochi, A., Imai, K., Benifla, M., Akiyama, T., Holowka, S., Rutka, J.T., Snead 3rd, O.C., and Otsubo, H. (2008). Epileptic spasms in older pediatric patients: MEG and ictal high-frequency oscillations suggest focal-onset seizures in a subset of epileptic spasms. Epilepsy Res. 78, 216-224.

Reis, G.M. and Duarte, I.D. (2006). Baclofen, an agonist at peripheral $G_{A B A_{B}}$ receptors, induces antinociception via activation of TEA-sensitive potassium channels. Br. J. Pharmacol. 149, 733-739.

Riikonen, R. (2014). Recent advances in the pharmacotherapy of infantile spasms. CNS Drugs 28, 279-290.

Roopun, A.K., Simonotto, J.D., Pierce, M.L., Jenkins, A., Nicholson, C., Schofield, I.S., Whittaker, R.G., Kaiser, M., Whittington, M.A., Traub, R.D., et al. (2010). A non-synaptic mechanism underlying interictal discharges in human epileptic neocortex. Proc. Natl. Acad. Sci. U.S.A. 107, 338-343.

Ruffin, V.A., Salameh, A.I., Boron, W.F., and Parker, M.D. (2014). Intracellular $\mathrm{pH}$ regulation by acid-base transporters in mammalian neurons. Front. Physiol. 5, 43.

Ruusuvuori, E. and Kaila, K. (2014). Carbonic anyhdrases and brain $\mathrm{pH}$ in the control of neuronal excitability. Subcell. Biochem. 75, 271-290.

Saxena, A. and Sampson, J.R. (2015). Epilepsy in tuberous sclerosis: phenotypes, mechanisms, and treatments. Semin. Neurol. 35, 269-276.

Schmitz, D., Schuchmann, S., Fisahn, A., Draguhn, A., Buhl, E.H., Petrasch-Parwez, R.E., Dermietzel, R., Heinemann, U., and Traub, R.D. (2001). Axo-axonal coupling: a novel mechanism for ultrafast neuronal communication. Neuron 31, 831-840.

Schwindt, P. and Crill, W. (1999). Mechanisms underlying burst and regular spiking evoked by dendritic depolarization in layer 5 cortical pyramidal neurons. J. Neurophysiol. 81, 1341-1354.

Siesjö, B.K. (1989). Calcium and cell death. Magnesium 8, 223-237. Simon, A., Traub, R.D., Vladimirov, N., Jenkins, A., Nicholson, C., Whittaker, R., Schofield, I., Clowry, G.J., Cunningham, M.O., and Whittington, M.A. (2014). Gap junction networks can generate both ripple-like and fast-ripple-like oscillations. Eur. J. Neurosci. 39, 46-60.

Smith, J.B., Westmoreland, B.F., Reagan, T.J., and Sandok, B.A. (1975). A distinctive clinical EEG profile in herpes simplex encephalitis. Mayo Clin. Proc. 50, 469-474. 
Sohn, J.W., Lee, D., Cho, H., Lim, W., Shin, H.S., Lee, S.H., and Ho, W.K. (2007). Receptor-specific inhibition of $\mathrm{GABA}_{\mathrm{B}}$-activated $\mathrm{K}^{+}$ currents by muscarinic and metabotropic glutamate receptors in immature rat hippocampus. J. Physiol. 580, 411-422.

Song, J.M., Hahn, J., Kim, S.H., and Chang, M.J. (2017). Efficacy of treatments for infantile spasms: a systematic review. Clin. Neuropharmacol. 40, 63-84.

Sotero de Menezes, M.A. and Rho, J.M. (2002). Clinical and electrographic features of epileptic spasms persisting beyond the second year of life. Epilepsia 43, 623-630.

Staley, K.J., Longacher, M., Bains, J.S., and Yee, A. (1998). Presynaptic modulation of CA3 network activity. Nat. Neurosci. 1, 201-209.

Steriade, M., Nuñez, A., and Amzica, F. (1993). A novel slow ( $<1 \mathrm{~Hz})$ oscillation of neocortical neurons in vivo: depolarizing and hyperpolarizing components. J. Neurosci. 13, 3252-3265.

Steriade, M., Amzica, F., and Contreras, D. (1994). Cortical and thalamic cellular correlates of electroencephalographic burst-suppression. Electroencephalogr. Clin. Neurophysiol. 90, 1-16.

Sun, L., Zhang, K., Li, J., Liu, D., Lu, Y., and Zhang, Z. (2012). An impairment of cortical GABAergic neurons is involved in alkalosis-induced brain dysfunctions. Biochem. Biophys. Res. Commun. 419, 627-631.

Tippens, A.L., Pare, J.F., Langwieser, N., Moosmang, S., Milner, T.A., Smith, Y., and Lee, A. (2008). Ultrastructural evidence for preand postsynaptic localization of Cav1.2 L-type $\mathrm{Ca}^{2+}$ channels in the rat hippocampus. J. Comp. Neurol. 506, 569-583.

Tombaugh, G.C. and Somjen, G.G. (1996). Effects of extracellular pH on voltage-gated $\mathrm{Na}^{+}, \mathrm{K}^{+}$and $\mathrm{Ca}^{2+}$ currents in isolated rat CA1 neurons. J. Physiol. 493, 719-732.

Tombaugh, G.C. and Somjen, G.G. (1997). Differential sensitivity to intracellular pH among high- and low-threshold $\mathrm{Ca}^{2+}$ currents in isolated rat CA1 neurons. J. Neurophysiol. 77, 639-653.

Tovar, K.R., Maher, B.J., and Westbrook, G.L. (2009). Direct actions of carbenoxolone on synaptic transmission and neuronal membrane properties. J. Neurophysiol. 102, 974-978.

Traub, R.D. and Whittington, MA. (2010). Cortical Oscillations in Health and Disease (New York, USA: Oxford University Press).

Traub, R.D., Schmitz, D., Jefferys, J.G.R., and Draguhn, A. (1999). High-frequency population oscillations are predicted to occur in hippocampal pyramidal neuronal networks interconnected by axonal gap junctions. Neuroscience 92, 407-426.

Traub, R.D., Whittington, M.A., Buhl, E.H., LeBeau, F.E.N., Bibbig, A., Boyd, S., Cross, H., and Baldeweg, T. (2001). A possible role for gap junctions in generation of very fast EEG oscillations preced- ing the onset of, and perhaps initiating, seizures. Epilepsia 42, 153-170.

Traub, R.D., Draguhn, A., Whittington, M.A., Baldeweg, T., Bibbig, A., Buhl, E.H., and Schmitz, D. (2002). Axonal gap junctions between principal neurons: A novel source of network oscillations, and perhaps epileptogenesis. Rev. Neurosci. 13, 1-30.

Traub, R.D., Contreras, D., Cunningham, M.O., Murray, H., LeBeau, F.E.N., Roopun, A., Bibbig, A., Wilent, W.B., Higley, M.J., and Whittington, M.A. (2005). Single-column thalamocortical network model exhibiting gamma oscillations, sleep spindles and epileptogenic bursts. J. Neurophysiol. 93, 2194-2232.

Traub, R.D., Duncan, R., Russell, A.J.C., Baldeweg, T., Tu, Y., Cunningham, M.O., and Whittington, M.A. (2010). Spatiotemporal patterns of electrocorticographic very fast oscillations $(>80 \mathrm{~Hz})$ consistent with a network model based on electrical coupling between principal neurons. Epilepsia 51, 1587-1597.

Traub, R.D., Whittington, M.A., Gutiérrez, R., and Draguhn, A. (2018). Electrical coupling between hippocampal neurons: contrasting roles of principal cell gap junctions and interneuron gap junctions. Cell Tissue Res. 373, 671-691.

Wang, S.J. (2005). Activation of neuropeptide YY1 receptors inhibits glutamate release through reduction of voltage-dependent $\mathrm{Ca}^{2+}$ entry in the rat cerebral cortex nerve terminals: suppression of this inhibitory effect by the protein kinase C-dependent facilitatory pathway. Neuroscience 134, 987-1000.

Wang, Y., Barakat, A., and Zhou, H. (2010). Electrotonic coupling between pyramidal neurons in the neocortex. PLoS One 5, e10253.

Westmoreland, B.F., Blume, W.T., and Gomez, M.R. (1976). Generalized sharp and slow wave and electrodecremental seizure pattern in subacute sclerosing panencephalitis. Mayo Clin. Proc. 51, 107-111.

Whittington, M.A., Stanford, I.M., Colling, S.B., Jefferys, J.G.R., and Traub, R.D. (1997). Spatiotemporal patterns of $\gamma$ frequency oscillations tetanically induced in the rat hippocampal slice. J. Physiol. 502, 591-607.

Williams, S.R. and Stuart, G.J. (1999). Mechanisms and consequences of action potential burst firing in rat neocortical pyramidal neurons. J. Physiol. 521, 467-482.

Yamatogi, Y. and Ohtahara, S. (1981). Age-dependent epileptic encephalopathy: a longitudinal study. Folia Psychiatr. Neurol. Jpn. 35, 321-332.

Yashiro, K. and Philpot, B.D. (2008). Regulation of NMDA receptor subunit expression and its implications for LTD, LTP, and metaplasticity. Neuropharmacology 55, 1081-1094.

Zhang, F., Lin, Y.A., Kannan, S., and Kannan, R.M. (2016). Targeting specific cells in the brain with nanomedicines for CNS therapies. J. Control Release 240, 212-226. 